\title{
The First High-Quality Genome Assembly and Data Analysis of the Malaysian mahseer (Tor tambroides)
}

\author{
Melinda Mei Lin Lau ${ }^{a}$, Leonard Whye Kit Lima, Hung Hui Chung ${ }^{a^{*}}$ and Han Ming \\ $\operatorname{Gan}^{\mathbf{b}, \mathbf{c}}$
}

${ }^{a}$ Faculty of Resource Science and Technology, Universiti Malaysia Sarawak, 94300 Kota

Samarahan, Sarawak, Malaysia.

${ }^{b}$ GeneSEQ Sdn Bhd, Bandar Bukit Beruntung, 48300 Rawang, Selangor, Malaysia

${ }^{c}$ Centre for Integrative Ecology, School of Life and Environmental Sciences, Deakin

University, Geelong, Victoria, Australia

*Corresponding author: Hung Hui Chung (hhchung@unimas.my)

\begin{abstract}
The Malaysian mahseer (Tor tambroides), one of the most valuable freshwater fish in the world, is mainly targeted for human consumption. The mitogenomic data of this species is available to date, but the genomic information is still lacking. For the first time, we sequenced the whole genome of an adult fish on both Illumina and Nanopore platforms. The hybrid genome assembly had resulted in a sum of $1.5 \mathrm{~Gb}$ genomic sequence from the 44,726 contigs found with $44 \mathrm{~kb} \mathrm{N50} \mathrm{length} \mathrm{and} \mathrm{BUSCO} \mathrm{genome} \mathrm{completeness} \mathrm{of} 84.3 \%$. Four types of SSRs had been detected and identified within the genome with a greater AT abundance than that of GC. Predicted protein sequences had been functionally annotated to public databases, namely GO, KEGG and COG. A maximum likelihood phylogenomic tree containing 53 Actinopterygii species and two outgroups was constructed, providing first insights into the genome-based evolutionary relationship of T. tambroides with other rayfinned fish. These data are crucial in facilitating the study of population genomics, species identification, morphological variations, and evolutionary biology, which are helpful in the conservation of this species.
\end{abstract}

Keywords: Genome; Gene annotation; Tor tambroides; Phylogenetic; Functional annotation

\section{Introduction}

The Malaysian mahseer, Tor tambroides (Bleeker, 1854), one of the members of the family Cyprinidae, is a widespread species found in aquaculture and fisheries mainly targeted for human consumption (Kottelat et al., 2018). It is commonly named Kelah or Empurau in Malaysia and Jurung, Indonesia (Jaafar et al., 2021). As a true mahseer (Tor spp.), it can be found in rapidly-flowing waters with rocky bottoms (Shreshtha, 1997). Together with Tor tambra and Tor dourenensis, it is one of the three Tor spp. found in freshwaters of Malaysia, and among the 16 Tor spp. found worldwide (Ng, 2004). 
Like other Tor spp., T. tambroides is endangered by environmental degradation within their habitat, causing an elevating shrink in their population size in recent years (Ingram et al., 2005). Anthropogenic modification of rivers, including agricultural activities, logging, and deforestations, had interrupted and reduced the water flow within its habitat. Consequently, such actions not only shrink the population size of T. tambroides and other Tor spp., but it is also associated with impacts on the aquatic environment. Despite environmental issues, $T$. tambroides are also at threat from overfishing with the usage of hooks, nets, and dynamites. However, there is currently no information on the rate of these losses (Kottelat et al., 2018).

It resides a wide range of freshwaters, including Brunei Darussalam, Yunnan China, Indonesia (Kalimantan, Jawa, and Sumatera), Lao, Malaysia (Peninsular, Sabah, and Sarawak) and Thailand (Kottelat 2018). Despite its comprehensive habitat coverage, its distant population can probably be different, leaving its taxonomy still vague. Its body is covered with scales depending on locality, such as silver, bronze, and reddish.

Although the presence of an upper median projection can be observed in T. tambroides, its other features, including equal caudal fin lobe, long lower median lobe, sub-terminal mouth position and pointed rostrum hood, were shared closely with other Tor spp., making it difficult to be distinguished (Jaafar et al., 2021). Therefore, disentangling Tor spp. via lips polymorphisms and median lobes resulting from direct environmental influences is discouraged due to lack of direct evidence (Roberts \& Khaironizam, 2008). Unpublished research had emphasised the reduction in lips and lobe size and the loss of red colour when the fishes from Sungai Tembat, Terengganu, were kept in captivity for more than two years (Walton et al., 2019). However, such polymorphism is yet to be observed in nature and thus remains deficient.

The accumulation of significant genetic and/or morphological differences among Tor spp distributed across Indonesia and Malaysia urged the revision of Tor taxonomy. Studies had been done aiming to resolve the ambiguous taxonomical status of Tor spp. by looking into its phylogenetic relationship through mitochondrial DNA, Cytochrome c Oxidase Subunit I (COX1) gene, Cytochrome b, ATPase $6 / 8$ gene, 16S rRNA gene, microsatellite, and SNP markers (Walton et al., 2017; Jaafar et al., 2021; Lim et al., 2021a). However, to date, the whole genome and transcriptome sequences of Tor spp. are still unavailable, except for a few studies that had reviewed its conservation status, conducted a gut metagenomic analysis, as well as sequenced the transcriptome of T. tambra (Lau et al., 2021a; Lau et al., 2021b; Lau et al., 2021c). Genomic and transcriptomic sequencing of Tor species is necessary to provide a more powerful tool that continues to resolve and address questions of species identification, evolutionary biology, morphological variations, sequences related to sex differentiation, growth, reproduction, and immune, which is helpful for further conservation of Tor species (Jaafar et al., 2021).

The rapid growth and expansion of the aquaculture industry had improved fish production as compared to traditional fishing. T. tambroides is one of the notable species found in the aquaculture industry due to its high nutritional value and unique flesh taste. However, it has been found that the genetic variability decreases in captivity-held fishes, causing them to be more vulnerable to infections. Thus, it is necessary to comprehend the fish immune system and its underlying mechanisms in response to its exposure to ecotoxicological chemicals (Lim et al., 2018; Lim et al., 2021b). However, in general, the studies of the fish immune 
response are limited due to its complexity and lack of suitable reagents for classical immunological assays (Salinas \& Magadán, 2017). Similarly, as a slow grower fish, it is necessary to venture into the growth-related aspect of the T. tambroides genome as well, which is in line with the goal of fish farming of this species which faces knowledge-scarcity on growth improvement to date. Omics approaches, including genomics, transcriptomics, proteomics, and metabolomics, can develop high throughput outcomes and facilitate more novel findings.

In the recent years, with the booming of long-read sequencing technologies (Heather \& Chain, 2016), the implementation of combining both Illumina reads and Nanopore/PacBio reads can be found in several studies (Austin et al., 2017; Tan et al., 2018; Lim et al., 2021c; Lim et al., 2022). Integration of short but accurate Illumina reads with long but less accurate Nanopore/PacBio reads could enhance the completeness of the assembled genome than assemblies based on Illumina reads only (Austin et al., 2017; Tan et al., 2018; Lim et al., 2021c; Lim et al., 2022). Thus, in this study, we sequenced and reported on the first genomic data of T. tambroides. We also functionally annotated the genome of T. tambroides to KEGG, GO, and COG databases and further identified its immune-related genes. Furthermore, we inferred the phylogenetic relationship of T. tambroides with other Actinopterygii fishes based on the BUSCO supermatrix data. It is hoped that these data generated from this study can be channeled for the improvement studies that are driven along with the conservation endeavors of this fish species.

\section{Experimental Design, Materials and Methods}

\section{Sampling and DNA extraction}

An adult T. tambroides (voucher ID: ASD03018) was sampled from a local aquaculture farm, with its locality reported in previous studies (Lau et al., 2021c; Lim et al., 2021). The fish had been deposited as voucher specimens in the fish museum located at the Faculty of Resource Science and Technology, Universiti Malaysia Sarawak. The fish was euthanised, and $50 \mathrm{mg}$ of its muscle tissue was used for genomic DNA extraction using the DTAB-CTAB DNA extraction kit (GeneReach Biotechnology Corp) according to the manufacturer's instructions.

\section{Species Verification}

Cytochrome c oxidase subunit I (COI) gene was amplified, and the PCR product was purified and sent for Sanger sequencing. The sequences were analysed using NCBI BLASTn and found to possess $100 \%$ similarity with the mitogenome sequences of T. tambroides reported by Lim et al. (2021) with the GenBank accession number MW471071.1.

\section{Library Construction and Whole Genome Sequencing}

Approximately one ug of gDNA was sheared to $350 \mathrm{bp}$ using a Bioruptor and directly used for PCR-free library preparation using the NEB Ultra Illumina library preparation kit (NEB, Ipswich, MA). The library was quantified with a Qubit (Invitrogen) and sequenced on a NovaSEQ6000 (Illumina, San Diego, CA) with 2 x 150 bp run configuration. Similarly, for Nanopore sequencing, one ug of unsheared gDNA was used as the input for LSK109 library 
preparation (Oxford Nanopore, UK) according to the manufacturer's instructions. The library was sequenced on two MinION flowcells. Nanopore reads were base-called from their fast5 files using Guppy version 4.4.1 (high accuracy mode).

\section{Sequence Data Processing and Assembly}

Illumina reads were trimmed with fastp (Chen et al., 2018), while the Nanopore reads were trimmed with porechop (Wick et al., 2017). The trimmed Nanopore reads and paired-end Illumina reads were used to perform a hybrid de novo assembly using Wengan v0.2 (Di Genova et al., 2021). Jellyfish v2.3.0 was used to obtain a frequency distribution of k-mer counting with the clean reads, producing kmer frequency distributions of 31-mers (Marçais \& Kingsford, 2011). These histograms were subsequently processed using GenomeScope, which estimates genomic size, repeat content and heterozygosity via kmer-based statistical approach (Vurture et al., 2017). QUAST v5.0.2 was used to evaluate various metrics of the T. tambroides genome (Mikheenko et al., 2018) using the parameter: read length 150 bp and max K-mer coverage 1,000. BUSCO v5.2.2 was used to evaluate the completeness of the assembled T. tambroides genome based on the single-copy orthologs represented in the actinopterygii_odb10 database (Manni et al., 2021).

\section{Detection of Repetitive Sequences and Prediction of Protein-Coding Genes}

Repetitive sequences in the assembled genomes were identified and masked using RepeatModeler2 and RepeatMasker, respectively. Previously generated transcriptomic reads (Lau et al., 2021b) were aligned to the repeat-masked genome assembly using HiSAT2 (Kim et al., 2015). The transcriptome alignment BAM file and the repeat-masked genome assembly were used as the input for protein-coding gene prediction in BRAKER2 (Bruna et al., 2021).

\section{SSR Analysis}

Simple sequence repeats (SSRs) analysis was identified using Kmer-SSR (https://github.com/ridgelab/Kmer-SSR) (Pickett et al., 2017) on the processed reads of the $T$. tambroides genome. Dinucleotides, trinucleotides, tetranucleotides, pentanucleotides and hexanucleotides were included in the SSRs analysis. Only SSRs with at least four repeats were selected for the study.

\section{Functional Annotation of Protein-Coding Genes}

The predicted protein sequences were functionally annotated to EggNOG mapper (evolutionary genealogy of genes: Non-supervised Orthologous Groups) with a minimum Evalue of 0.001 . Functional annotation of genes was performed by mapping against three public databases, GO (Gene ontology), KEGG (Kyoto Encyclopedia of Genes and Genomes), and COG (the Clusters of Orthologous Groups).

In addition, predicted protein sequences were mapped against several previously published growth- and immune-related genes based on literature review (Overturf et al., 2010; Palti, 2011; Vagner \& Santigosa, 2011; Zhenzhen et al., 2014; Hu et al., 2016; Ma et al., 2016; Chandhini \& Rejish, 2019; Lin et al., 2019; Dam et al., 2020; Damzamnn et al., 2020; Guan \& Qiu, 2020). 82 growth- and 31 immune-related genes (113 genes in total) were downloaded from the NCBI GenBank database (https://www.ncbi.nlm.nih.gov/) and used as references. Subsequently, the genes were further filtered based on a stringent E-value cutoff of $10^{-10}$. 


\section{Ortholog Inference and Phylogenetic Construction}

The Tor tambroides genome was assembled in this study, while other genome sequences used were obtained from NCBI (National Center for Biotechnology Information) and summarised in Table 1. A total of 50 species genomes together with 2 outgroups (additional species from Coelacanthiformes and Acipenseriformes) were included.

We had identified single-copy orthologous genes in each genome using BUSCO v5.2.2 (Benchmarking Universal Single-Copy Orthologs) (Manni et al., 2021) across all 53 Actinopterygii species. BUSCO was run with orthologs in actinopterygii_odb10 (updated 2021-02-19) using default parameters. All BUSCOs found in a single-copy and multi-copy for each species were used for phylogenetic analysis. Subsequently, BUSCO sequences were individually aligned with MUSCLE (Multiple Sequence Comparison by Log-Expectation) across all 53 species (Edgar, 2004). Gaps and unmatched sites were removed from the resulting multiple sequence alignments (MSAs) using trimAl (Capella-Gutiérrez et al., 2009). These trimmed MSAs were concatenated into a supermatrix. A maximum-likelihood (ML) phylogenetic tree was inferred from the supermatrix using IQ-TREE (Nguyen et al., 2015). Molecular Evolutionary Genetic Analysis (MEGA) v11.0.10 was used to analyse and view the generated phylogenetic tree (Kumar et al., 2018)

The complete genome sequence of $T$. tambroides reported in this study is available under NCBI Bioproject PRJNA708136 (https://submit.ncbi.nlm.nih.gov/subs/bioproject/ SUB9225867/overview). The sequencing reads in this study are also available under NCBI SRA entry SUB10492101 (https://submit.ncbi.nlm.nih.gov/subs/sra/SUB10492101).

\section{Ethics Statement}

All experiments comply with ARRIVE guidelines and were carried out in accordance with the U.K. Animals (Scientific Procedures) Act, 1986 and associated guidelines, EU Directive 2010/63/EU for animal experiments, or the National Institute of Health guide for the care and use of Laboratory animals (NIH Publications No. 8023, revised 1978). 
Table 1. Species found within class Actinopterygii obtained from NCBI were used in this study to build the Maximum-likelihood (ML; IQTREE) tree to infer the phylogenetic relationship of these fishes with T. tambroides. A total of 50 species with two outgroups were reported and classified into their respective residing environment, including freshwater, marine, or diadromous.

\begin{tabular}{|c|c|c|c|c|c|c|}
\hline & Species & Order & $\begin{array}{l}\text { Translated } \\
\text { CDS size } \\
(\mathrm{Mb})\end{array}$ & $\begin{array}{l}\text { BUSCO5 } \\
\text { completeness }\end{array}$ & $\begin{array}{l}\text { No. of } \\
\text { chromosomes }\end{array}$ & Accession Numbers \\
\hline \multirow[t]{23}{*}{ Freshwater } & Archocentrus centrarchus & Cichliformes & 13.4 & 99.6 & 24 & GCF_007364275.2 \\
\hline & Astyanax mexicanus & Characiformes & 13.7 & 98.6 & 25 & GCF_000372685.2 \\
\hline & Austrofundulus limnaeus & Cyprinodontiformes & 11.7 & 89.6 & 0 & GCF_001266775.1 \\
\hline & Betta splendens & Anabantiformes & 13.8 & 99.4 & 22 & GCF_900634795.3 \\
\hline & Carassius auratus & Cypriniformes & 20.8 & 99.3 & 60 & GCF_003368295.1 \\
\hline & Colossoma macropomum & Characiformes & 14.1 & 99.7 & 0 & GCF_904425465.1 \\
\hline & Coregonus clupeaformis & Salmoniformes & 21.1 & 98.6 & 41 & GCF_018398675.1 \\
\hline & Cyprinodon tularosa & Cyprinodontiformes & 13.3 & 99.0 & 0 & GCF_016077235.1 \\
\hline & Danio rerio & Cypriniformes & 17.3 & 97.3 & 25 & GCF_000002035.6 \\
\hline & Esox lucius & Esociformes & 14.9 & 99.7 & 26 & GCF_011004845.1 \\
\hline & Etheostoma cragini & Perciformes & 12.8 & 96.5 & 24 & GCF_013103735.1 \\
\hline & Etheostoma spectabile & Perciformes & 13.1 & 96.0 & 25 & GCF_008692095.1 \\
\hline & Haplochromis burtoni & Cichliformes & 14.7 & 98.1 & 1 & GCF_018398535.1 \\
\hline & Lepisosteus oculatus & Lepisosteiformes & 10.8 & 98.5 & 30 & GCF_000242695.1 \\
\hline & Melanotaenia boesemani & Atheriniformes & 13.6 & 99.8 & 25 & GCF_017639745.1 \\
\hline & Oncorhynchus mykiss & Salmoniformes & 24.3 & 99.7 & 33 & GCF_013265735.2 \\
\hline & Oreochromis niloticus & Cichliformes & 16.3 & 99.8 & 23 & GCF_001858045.2 \\
\hline & Oryzias latipes & Beloniformes & 13.5 & 98.5 & 25 & GCF_002234675.1 \\
\hline & Oryzias melastigma & Beloniformes & 13.1 & 98.2 & 25 & GCF_002922805.2 \\
\hline & Paramormyrops kingsleyae & Osteoglossiformes & 13.9 & 98.7 & 0 & GCF_002872115.1 \\
\hline & Poecilia reticulata & Cyprinodontiformes & 13.0 & 97.7 & 24 & GCF_000633615.1 \\
\hline & Perca flavescens & Perciformes & 13.1 & 99.6 & 25 & GCF_004354835.1 \\
\hline & Perca fluviatilis & Perciformes & 14.1 & 98.5 & 24 & GCF_010015445.1 \\
\hline
\end{tabular}




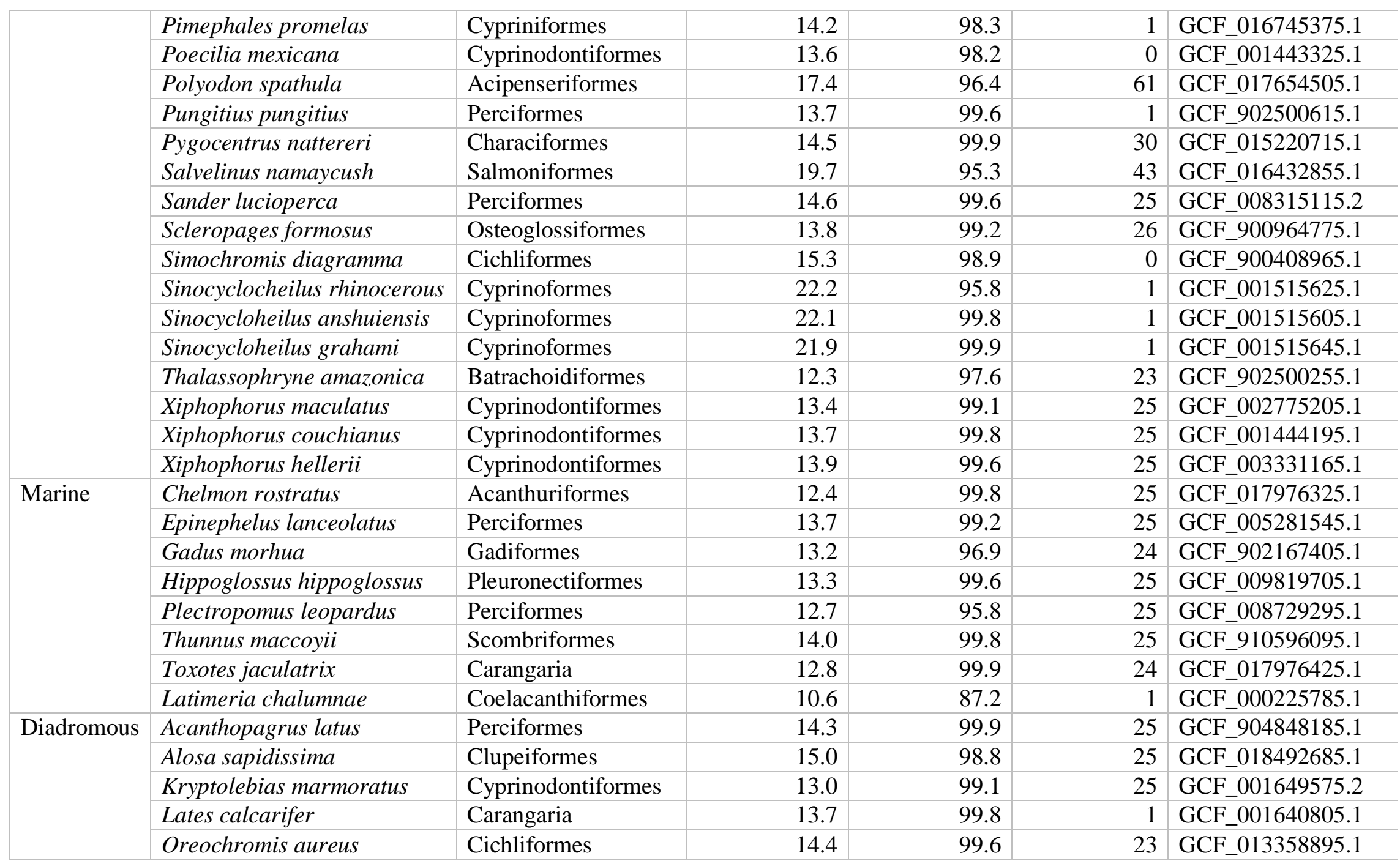




\section{Results \& Discussion}

\section{Characterisation of $T$. tambroides and its genome sequencing}

The genomic sequencing and assembly statistics of the target $T$. tambroides in this study were summarized in Table 2 . The total contig length is $1,235,136,976$ bp with 44,726 contigs. The longest contig length recorded is $445,922 \mathrm{bp}$. The contig GC content documented in this study is $36.55 \%$.

Table 2. Genomic sequencing and assembly statistics

\begin{tabular}{|l|l|}
\hline Total contig length & $1,235,136,976 \mathrm{bp}$ \\
\hline Number of contigs & 44,726 \\
\hline Longest contig length & $445,922 \mathrm{bp}$ \\
\hline Contig N50 length & 44,262 \\
\hline Contig GC (\%) content & 36.55 \\
\hline BUSCO Completeness (Actinopterygii_odb10) \\
\hline Actinopterygii_odb10: Complete BUSCOs & $84.3 \%(3069)$ \\
\hline Complete and single copy BUSCOs & $39.2 \%(1427)$ \\
\hline Complete and duplicated BUSCOs & $45.1 \%(1642)$ \\
\hline Missing BUSCOs & $8.3 \%(301)$ \\
\hline
\end{tabular}

The assembled clean reads of the T. tambroides genome were subjected to K-mer analysis using Jellyfish software and visualised using GenomeScope (K-mer:31), as shown in Figure 1. The $y$-axis had demonstrated the amount of K-mers found at each corresponding depth on the $\mathrm{x}$-axis. There is no heterozygous peak generated at 23, and a low heterozygosity level of $0.194 \%$ was recorded. The depth of the homozygous peak can be observed at 46 , which accounts for the identical 31-mers from both strands of DNA. The kmer-based statistical approach had revealed that $24.675 \%$ of the genomic content is repeated whereas $75.325 \%$ of the content is unique. The genome size of T. tambroides can be predicted by division of $\mathrm{K}$ mer number over K-mer depth. The k-mer number detected in this study is $69 \mathrm{~Gb}$. Therefore, the expected genome size is predicted as $1.5 \mathrm{~Gb}$.

The T. tambroides genome size of $1.5 \mathrm{~Gb}$ was found to locate within the range of Cyprinidae genome sizes, including grass carp (Ctenopharyngodon idella) and common carp (Cyprinus carpio) at $1.07 \mathrm{~Gb}$ (Wang et al., 2015) and $1.7 \mathrm{~Gb}$ (Xu et al., 2014), respectively. Besides, its GC\% content reported (36.55\%) was slightly lower than the $37.4 \%$ and $37.3 \%$ seen in $C$. idella and C. carpio. In general, a more outstanding GC content was found in seawater (usually above $40 \%$ ) than freshwater fish (less than $40 \%$ ), and also in migratory than a nonmigratory species (Lu \& Luo, 2020). Thus, it is suggested that the genomic GC content may be influenced by different living environments (Lu \& Luo, 2020). Besides, the contrary relationship between genomic size $(1.5 \mathrm{~Gb})$ and $\mathrm{GC}$ content $(36.55 \%)$ was shown in genome of $T$. tambroides. However, such assertion was insignificant based on a study reviewing 14 species, thus suggesting the collection of more genomic data for further validation (Lu \& Luo, 2020).

Repetitive elements accounted for $39.79 \%$ in T. tambroides genome, which is likely to be associated with its genome duplication. It is found to be in accordance to the repetitive elements found across order Cypriniformes species reporting to be around $35 \%$ to $40 \%$, 
including Danio rerio, Cyprinus carpio, Sinocycloheilus graham, Sinocycloheilus rhinocerous, Sinocycloheilus anshuiensis and Pimephales promelas (Yuan et al., 2018). Within teleost fish, researchers had found out that the expansion of repetitive elements may be the factor for the expansion of fish genome size as observed across 52 teleost species (Yuan et al., 2018). Having a high repetitive element content within the genome could speed up the generation of novel genes for adaptation purposes. However, an excessive amount of it would bring to abnormal combination and splicing, resulting in unstable genomes (Hong, 1998). In short, it is discouraged for unlimited growth of repetitive elements with its genomic size but limited to certain levels and shaped under specific natural selection (Yuan et al., 2018).

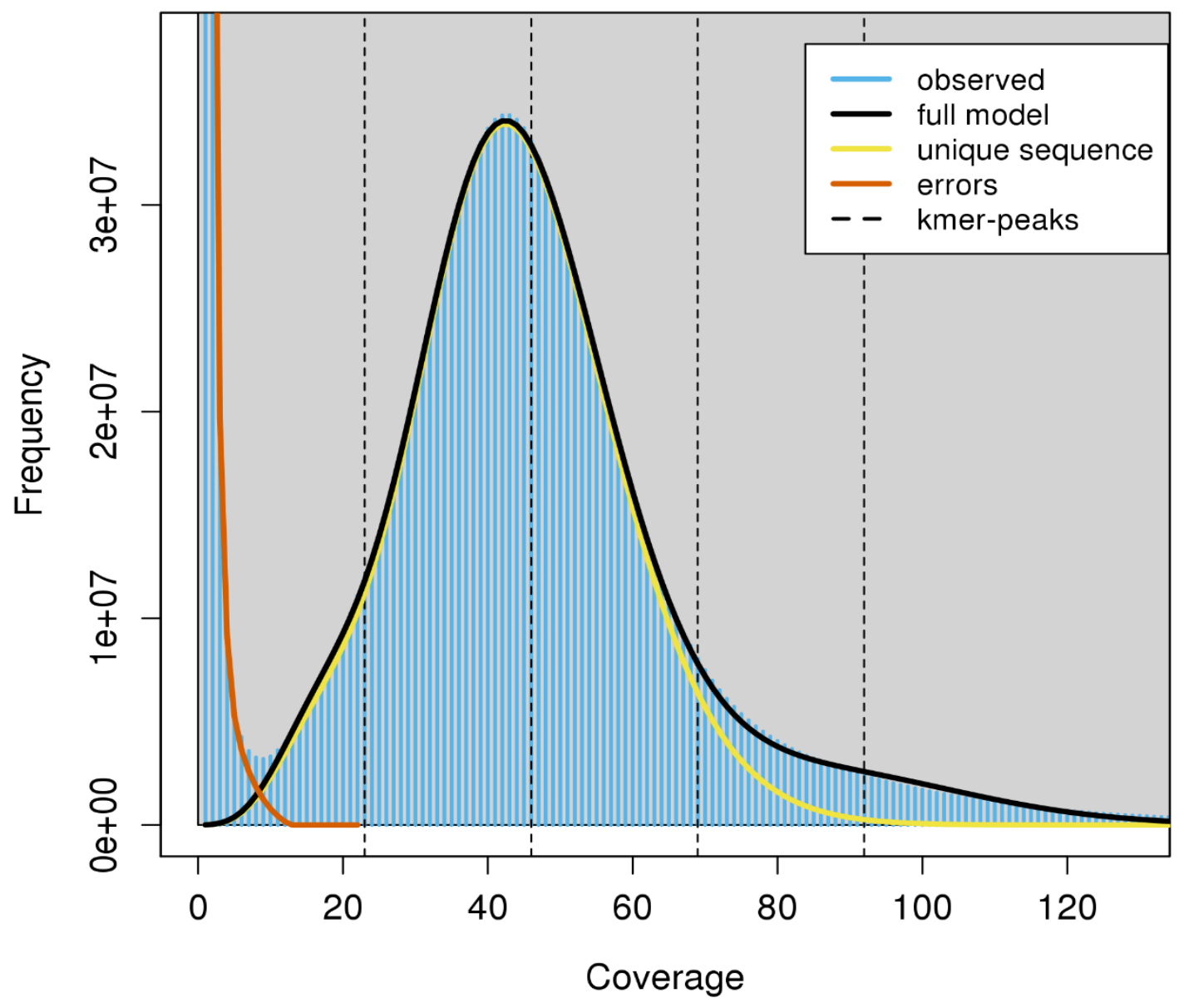

Figure 1. Estimation of genome size, repeat content and heterozygosity by GenomeScope, based on 31-mers (read length $=150 \mathrm{bp}$; kmer max coverage at 1000).

\section{SSR Analysis}

A total of 392,346 SSRs had been successfully identified from the genome of T. tambroides. Four types of SSRs had been tabulated with their length, total counts, average length and 
distribution (Table 3) while Figure 2 is showing the composition of each type of SSR within the genome of $T$. tambroides. The dinucleotide repeats had covered up to $70 \%$ of the entire SSR population, encompassing 275,715 SSRs. The trinucleotide and tetranucleotide repeats counts are 59,978 (15\%) and 49,089 (13\%), and they are ranked second and third out of all the four SSRs. The remaining $2 \%$ SSRs were 7,388 pentanucleotide repeats found within the genome of $T$. tambroides. The top three highest frequency dinucleotide repeats SSRs are AT/TA $(1,058,829)$, AC/GT $(71,569)$ and CA/TG $(70,249)$ composing up to $89 \%$ of the entire dinucleotide SSRs (Figure 3). The top three trinucleotide repeats covered up to onethird of the trinucleotide SSR repeats, namely AAT/ATT, TTA/TAA and TAT/ATA. As for the tetranucleotide repeats SSRs, the AGAT/ATCT, GATA/TATC and TCTA/TCGA counts were $6,209,5,386$ and 3,826 respectively, covering up to $30 \%$ of the entire tetranucleotide SSRs. Correspondingly, $18 \%$ of the pentanucleotide repeat SSRs were AAAAT/ATTTT (6.42\%), ATAAT/ATTAT (6.13\%) and TTTTA/TAAAA (5.96\%) respectively. Overall, the dinucleotides SSRs, namely AT/TA (26.97\%), AC/GT (25.96\%) and CA/TG (17.90\%) had occupied more than half of the SSR population found within the genome of T. tambroides.

SSRs allow faster adaptation to environmental stress through increment of DNA quantity and raw material for adaptative evolution during genome evolution. Thus, it can be said the mutation rate of microsatellite is dependent on the repeated unit length with a more common observation of mono- and dinucleotide repeats as compared to other repeats with longer lengths due to respective stability (Schlotterer, 2000). The frequency of tetranucleotide was higher than trinucleotide within the genome of T. tambroides, which was shown in other rayfinned fishes as well (Lei et al., 2021). Less occurrence of trinucleotide SSRs repeats can be due to its attribution as a triplet code to form part of the gene and also the presence of a mismatch repair system in the exonic region to maintain greater trinucleotide repeats (Lei et al., 2021).

SSR repeats with poly $(\mathrm{A} / \mathrm{T})$ tracts were found in a greater abundance than repeats with poly $(\mathrm{G} / \mathrm{C})$ tracts in other ray-finned fishes across all types of SSRs including dinucleotide, trinucleotide, tetranucleotide and pentanucleotide (Lei et al., 2021). The higher frequency of poly (A) can be due to the re-integration of the processed genes from mRNA back into the genome with an attached poly (A) tail, while poly $(\mathrm{G} / \mathrm{C})$ is not included in this integrative mechanism (Lei et al., 2021). In addition, greater poly (A) occurrence can be explained through the formation of pseudogenes and its necessity in the universal retrotransposon (Toth et al., 2000; Borodulina et al., 2016). The (GC) repeats are more stable than (AT) repeats thus increasing the difficulty to be slipped during replication (Gur-Arie et al., 2000).

Dinucleotides AT/TA is the common microsatellites repeat found across the fish genomes (Lei et al., 2021) which is observed within the genome of T. tambroides as well. Furthermore, for trinucleotide repeats, the occurrence of (CCG) n (16 counts) and (ACG) n (2572 counts; $5 \%$ ) repeats were rare in $T$. tambroides as well. This phenomenon can be explained by the presence of the highly mutable $\mathrm{CpG}$ dinucleotide within the motif due to methylation (Lei et al., 2021). While in tetranucleotide repeats, the $\mathrm{G}+\mathrm{C}$ content of SSRs was observed in a lower frequency because of its influence on the mutation rate as there is no statistical significance between $25 \% \mathrm{G}+\mathrm{C}$ content but each was significant difference from the $50 \% \mathrm{G}+\mathrm{C}$ repeat content (Eckert et al., 2002). 
The repetitive element found within the genome of $T$. tambroides was reported as $4.15 \%$. It had been reported previously that the expansion of repetitive elements would cause a further expansion in the fish genome Therefore, it can be said that the fish genome size is positively correlated with the repetitive elements (Yuan et al., 2018). However, a study reviewing the SSR across 14 fish species contradicts the statement (Lei et al., 2021). The generation of novel genes for adaptation can be accelerated with the presence of high repetitive element content, for instance in salmon, which is likely to be associated with genome duplication (Lien et al., 2016). Besides, the variation observed within microsatellites can be due to differential selective constraints causing accumulated preference for different microsatellite types (Lei et al., 2021). However, overburden could cause abnormal recombination and splicing, resulting in genome instability (Yuan et al., 2018). In short, it can be concluded that the repetitive elements must be limited to shape under specific natural selection by the environment. Its unambiguous role in genomic function still remains to be explored.

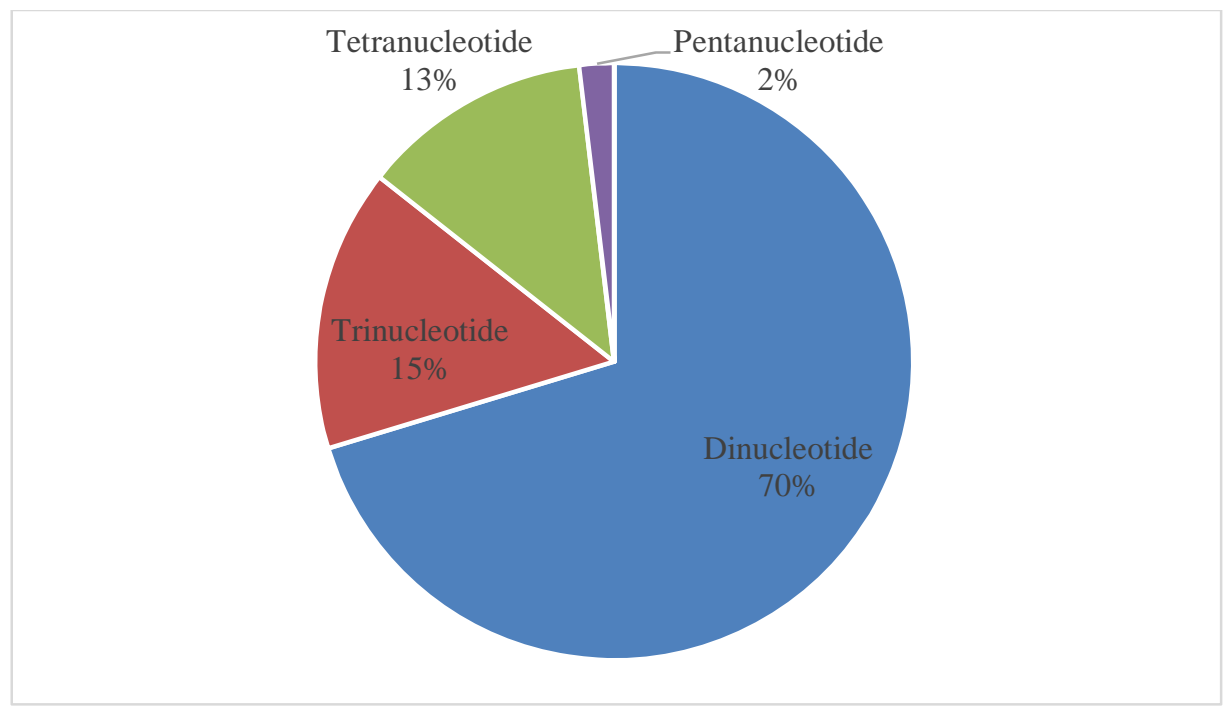

Figure 2. The composition of dinucleotide, trinucleotide, tetranucleotide, pentanucleotide and hexanucleotide SSRs identified from the genome of T. tambroides. 


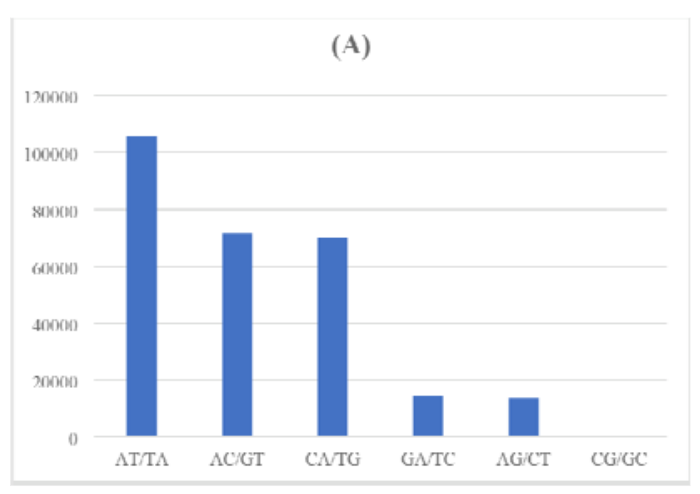

(C)

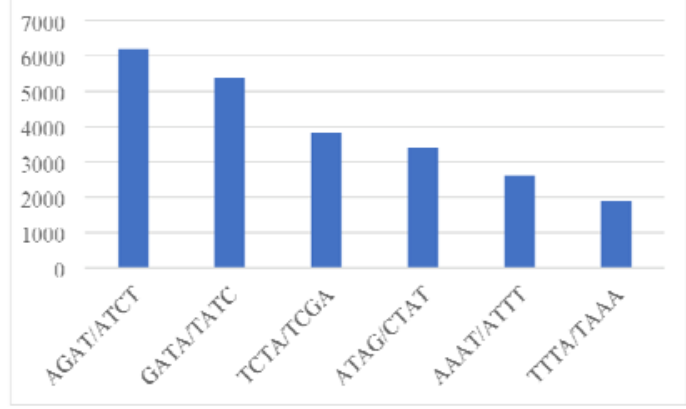

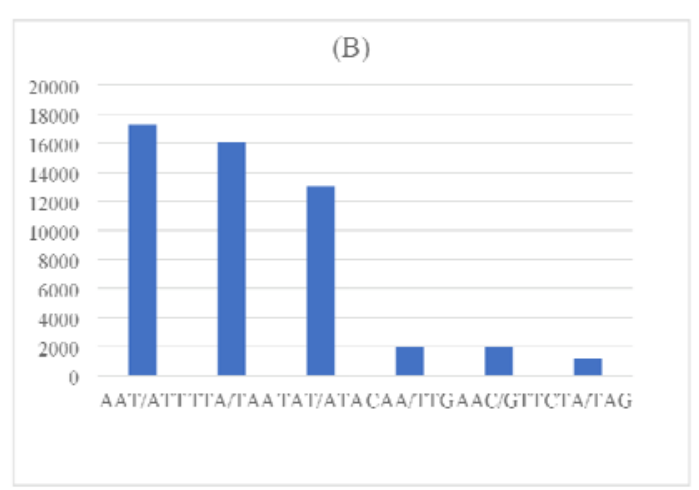

(D)

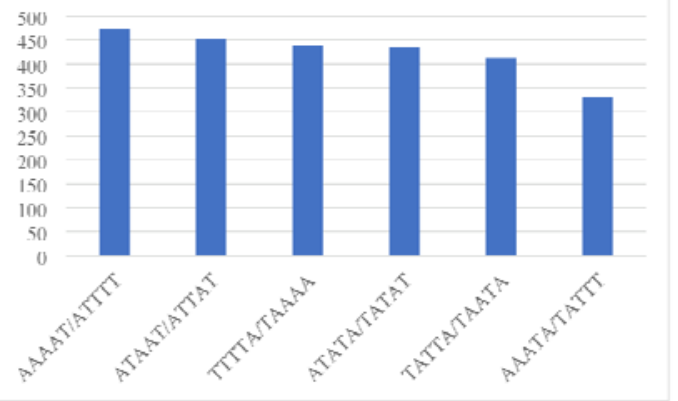

Figure 3. SSRs percentage graph with selected top six frequency SSRs from each group: (A) dinucleotide repeats, (B) trinucleotide repeats, (C) tetranucleotide repeats, (D) pentatetranucleotide repeats.

Table 3. The number, total length and average length of five different types of SSRs found within the genome of T. tambroides.

\begin{tabular}{|l|c|c|c|c|}
\hline $\begin{array}{l}\text { Nucleotide } \\
\text { Repeats }\end{array}$ & $\begin{array}{c}\text { Total } \\
\text { counts }\end{array}$ & $\begin{array}{c}\text { Total length } \\
(\mathrm{bp})\end{array}$ & $\begin{array}{c}\text { Average } \\
\text { length }(\mathrm{bp})\end{array}$ & $\begin{array}{c}\text { Percentage found in the } \\
\text { whole genome }(\%)\end{array}$ \\
\hline Dinucleotide & 173425 & 1387400 & 8.000 & 0.112 \\
\hline Trinucleotide & 21201 & 133850 & 6.313 & 0.011 \\
\hline Tetranucleotide & 78303 & 332947 & 4.252 & 0.027 \\
\hline Pentanucleotide & 35009 & 147053 & 4.200 & 0.012 \\
\hline Hexanucleotide & 19077 & 79193 & 4.151 & 0.006 \\
\hline
\end{tabular}

\section{Functional Annotation of T. tambroides}

For functional annotation of $T$. tambroides genome, coding region was extracted using Interproscan (Jones et al., 2014), generating 96,736 predicted non-redundant protein sequences. Subsequently, the sequences were annotated using eggNOG mapper to map the predicted protein sequences to GO, KEGG, and COG databases. The sequence length of each 
unigene ranged from $<100 \mathrm{bp}$ to $>2000 \mathrm{bp}$ (Figure 4), which showed a decreasing trend as the length increases. Table 4 shows the number of unigenes annotated to either GO, KEGG or COG, unigenes annotated to at least one of the databases and all the databases. A total of 42,694 (75.19\%), 25,560 (45.01\%), and 55,981 (98.58\%) of unigenes were annotated to GO, KEGG, and COG databases respectively. Out of a total of 56,785 annotated unigenes, 56,094 $(98.78 \%)$ of the unigenes had been found to have a significant match to at least one of the databases while $21,878(38.53 \%)$ unigenes portrayed a notable match to all the three databases. Figure 5 illustrates the distribution of unigenes across GO, KEGG, and COG databases.

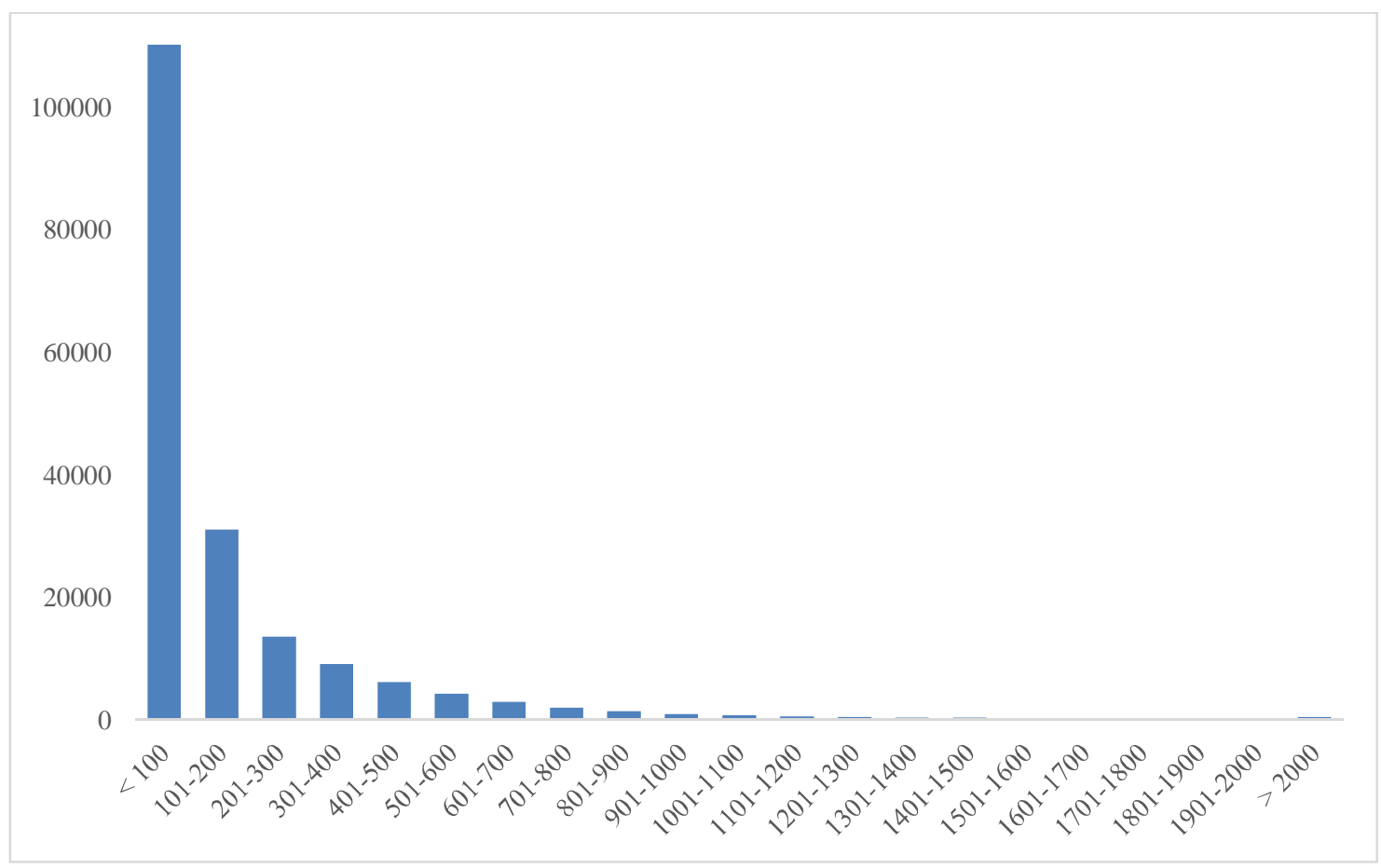

Figure 4. Length distribution of unigenes of T. tambroides. 


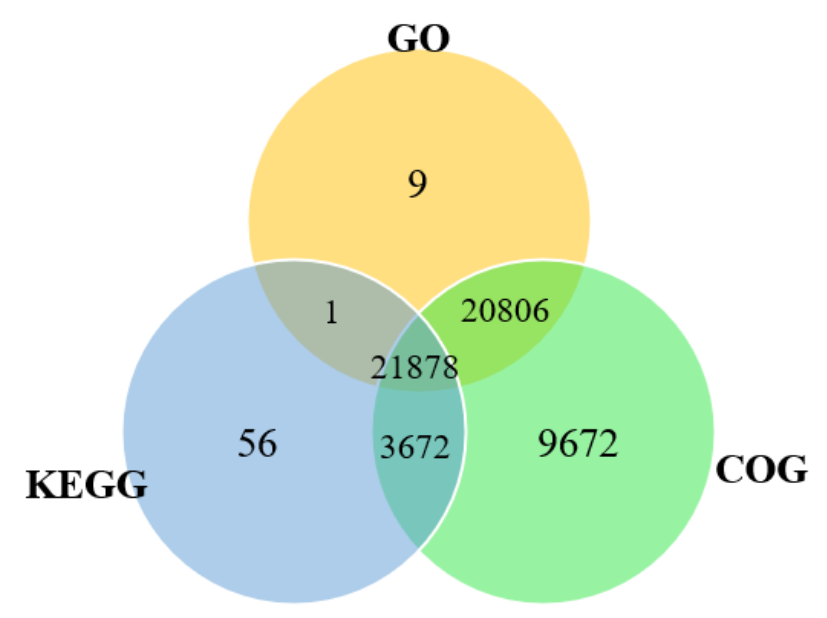

Figure 5. Venn diagram showing differences and similarity of unigenes of T. tambroides annotated to GO, KEGG, and COG databases.

Table 4. Functional annotation of unigenes to the various database.

\begin{tabular}{|l|l|l|}
\hline Database & Number of Unigenes & Percentage $(\%)$ \\
\hline GO & 42,694 & 75.19 \\
\hline KEGG & 25,560 & 45.01 \\
\hline COG & 55,981 & 98.58 \\
\hline Annotated in at least one database & 56,094 & 98.78 \\
\hline Annotated in all database & 21,878 & 38.53 \\
\hline All unigenes & 56,785 & 100.00 \\
\hline
\end{tabular}

Annotation of T. tambroides genome to each main ontology of GO database was shown in Figure 6, including biological process, molecular functions, and cellular components. Under biological process, metabolism $(4475 ; 6.56 \%)$ had the greatest count, followed by development $(3337 ; 4.89 \%)$ and catalytic activity $(2149 ; 3.15 \%)$. On the other hand, a total of 1239 counts $(1.82 \%)$ were responsible for binding, $761(1.12 \%)$ accounted for transferase activity and $688(1.01 \%)$ accounted for protein binding, under the molecular function category. Furthermore, under the cellular components category, 2139 (3.14\%) were accounted for cell organization and biogenesis while $1672(2.45 \%)$ and $1284(1.88 \%)$ were categorized as cell and intracellular respectively.

Another annotation was performed towards a widely-used reference database KEGG equipped with multiple pathways for better integration and interpretation of large-scale datasets. T. tambroides genome had successfully mapped towards 304 known KEGG pathways (Figure 7), including organismal system, cellular processes, environmental information processing, genetic information processing and metabolism. Out of the five main aforementioned categories, the largest count $(36340 ; 39.4 \%)$ is from organismal system whilst genetic information processing $(4324 ; 4.69 \%)$ had the lowest count. The categories reported on the greatest number of counts were signal transduction from environmental information processing $(19577 ; 21.22 \%)$, endocrine system from organismal system (9415; 
$8.79 \%)$ and immune system $(8110 ; 10.21 \%)$ from organismal system. Figure 8 depicts the top ten KEGG cluster components found in each main aforementioned category. The top three largest count can be observed in metabolic pathway $(4302 ; 4.66 \%)$, PI3K-Akt signaling pathway $(1500 ; 1.63 \%)$ and MAPK signaling pathway $(1464 ; 1.59 \%)$ from signal transduction.

Figure 9 illustrates the classification of 96,736 predicted protein sequences towards COG database consisting of clusters of orthologous groups. There were altogether $25 \mathrm{COG}$ classifications and can be grouped under four main clusters: information storage and processing $(8906 ; 15.17 \%)$, cellular processes and signaling $(25248 ; 43.01 \%)$, metabolism $(8402 ; 14.31 \%)$ and poorly characterized $(16152 ; 27.51 \%)$. Among all the clusters, greater counts were originated from function unknown $(16152 ; 27.51 \%)$, followed by signal transduction mechanism $(14284 ; 24.33 \%)$ and transcription $(4455 ; 7.59 \%)$. Overall, the genome of $T$. tambroides is enriched with gene families in the categories of signal transduction, endocrine system, immune system and metabolic pathways. It is found to be consistent with the common carp genome (Xu et al., 2014) and Javan mahseer transcriptome (Lau et al., 2021b). 


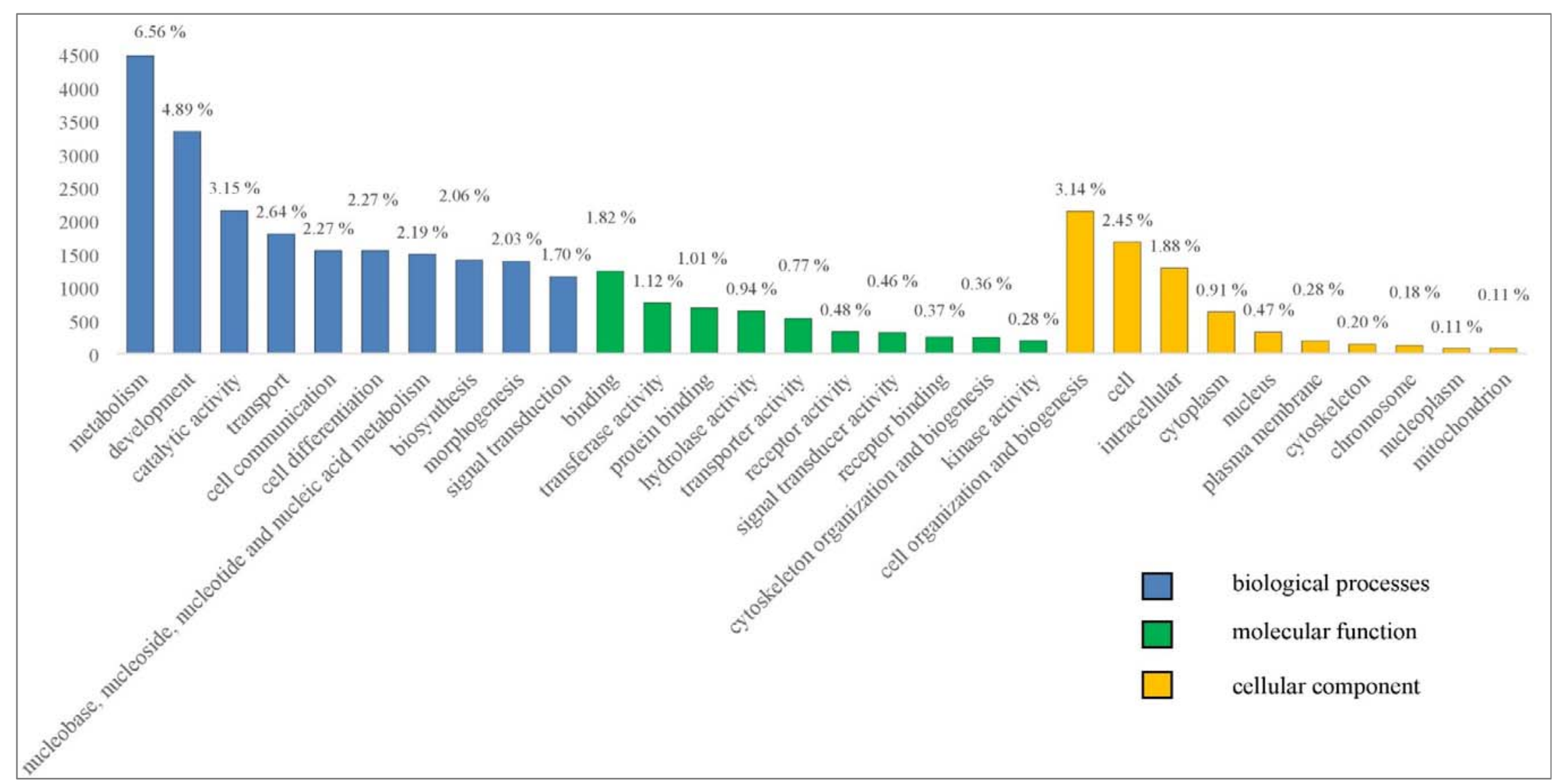

Figure 6. GO classifications 


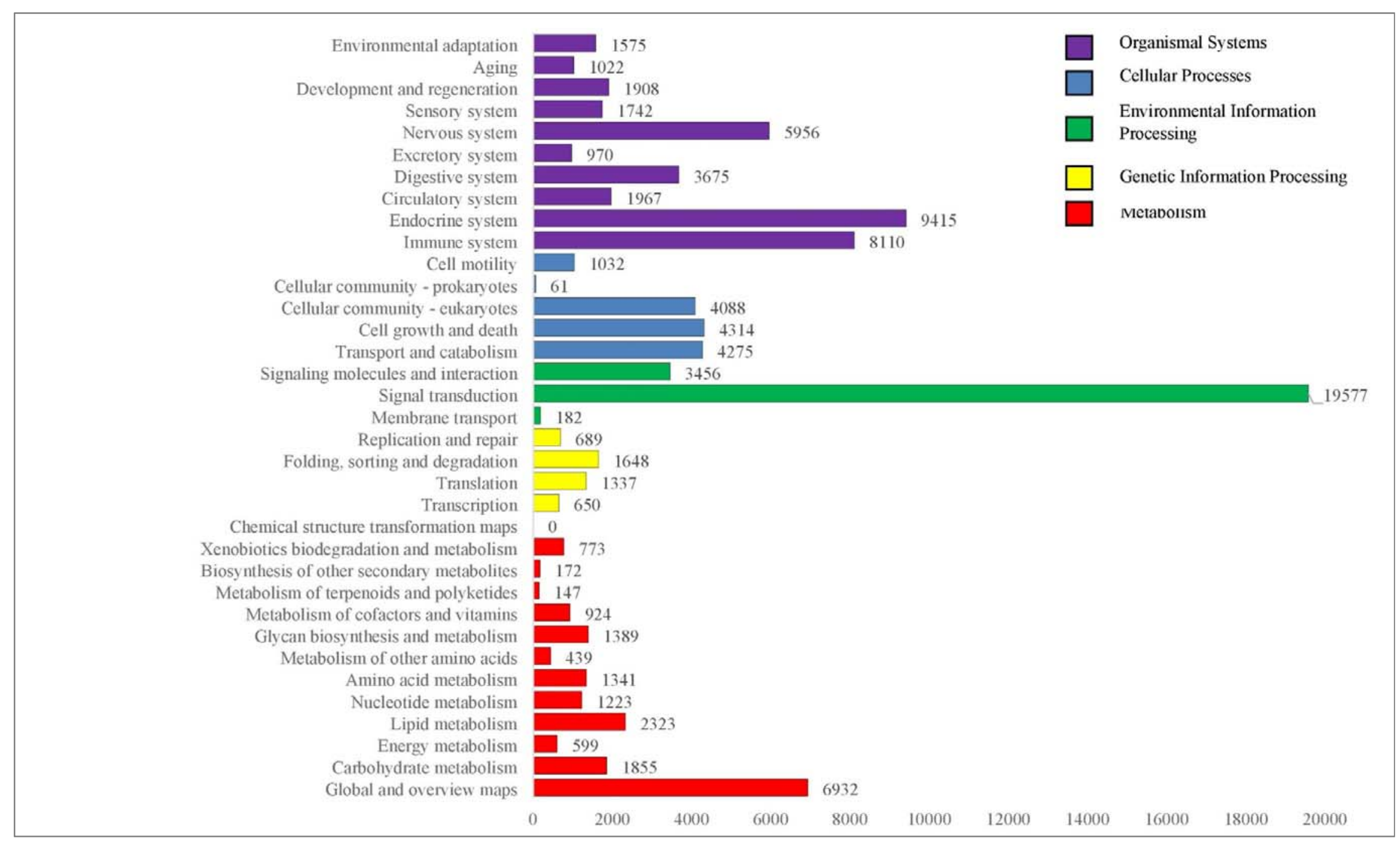

Figure 7. KEGG classifications 


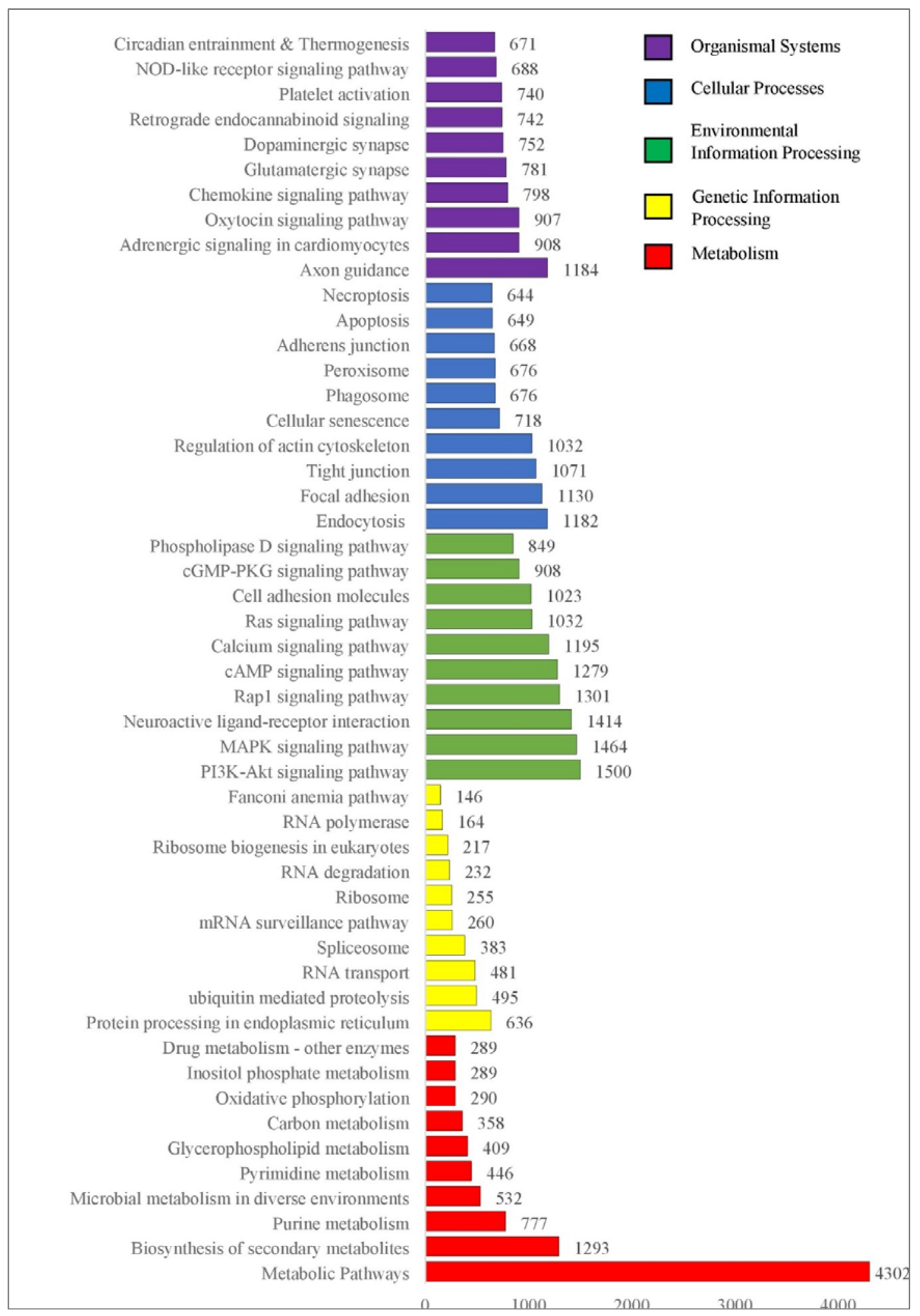

Figure 8. Top 10 KEGG classification 


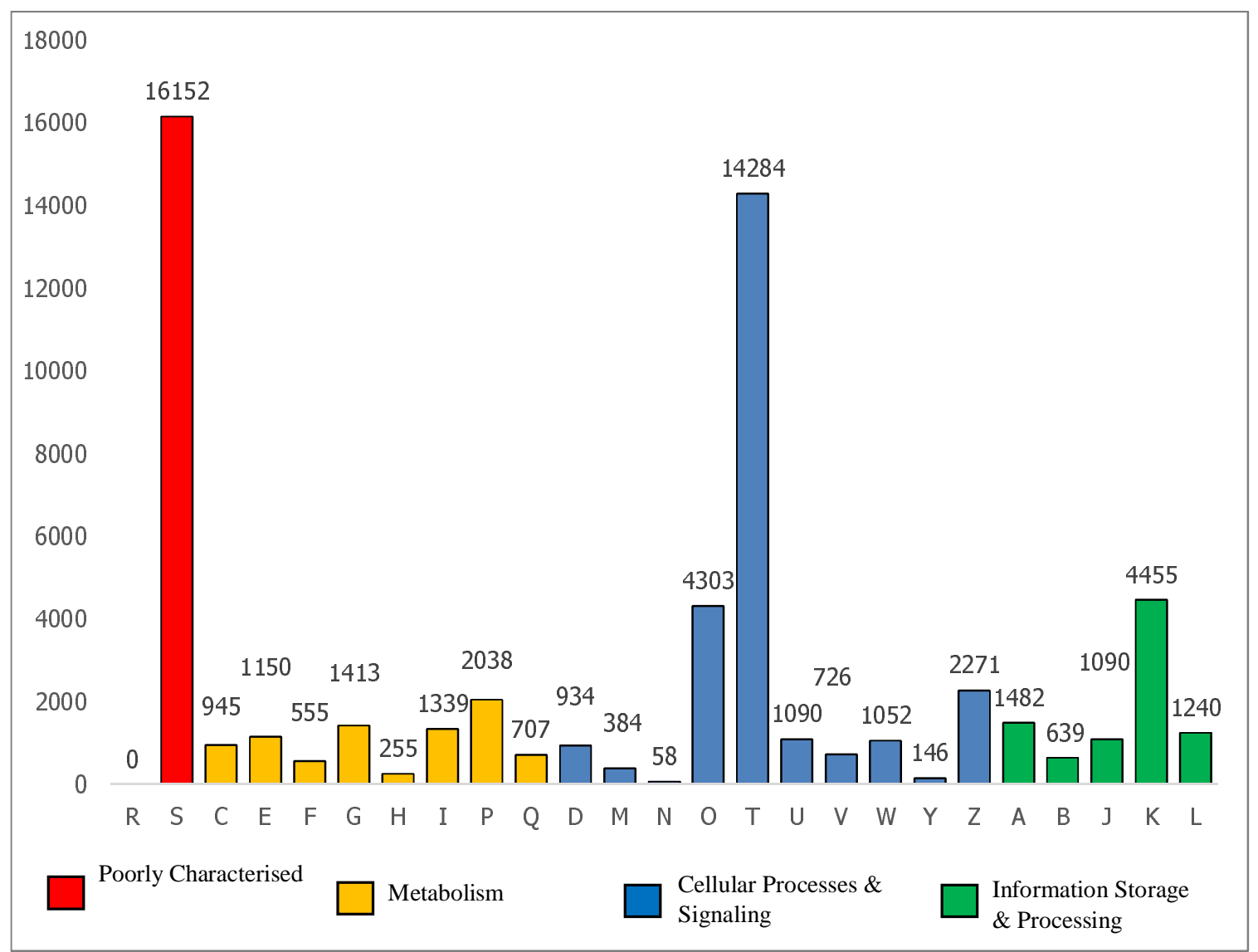

Figure 9. COG classifications
R: General function prediction only

S: Function unknown

$\mathrm{C}$ : Energy production and conversion

E: Amino acid transport and metabolism

F: Nucleotide transport and metabolism

G: Carbohydrate transport and metabolism

$\mathrm{H}$ : Coenzyme transport and metabolism

I: Lipid transport and metabolism

P: Inorganic ion transport and metabolism

Q: Secondary metabolites biosynthesis, transport and metabolism

D: Cell cycle control, cell division, chromosome partitioning

M: Cell wall/membrane/envelope biogenesis

$\mathrm{N}$ : Cell motility

O: Posttranslational modification, protein turnover, chaperones

T: Signal transduction mechanism

U: Intracellular trafficking, secretion and vesicular transport

V: Defence mechanisms

W: Extracellular structures

Y: Nuclear structures

Z: Cytoskeleton

A: RNA processing and modification

B: Chromatin structure and dynamics

J: Translation, ribosomal structure and biogenesis

K: Transcription

L: Replication, recombination and repair 


\section{Immunity-related Annotation}

To characterize a comprehensive defense landscape of $T$. tambroides against pathogenic infections, the genomic sequences of $T$. tambroides had been functionally annotated to identify pathways and genes associated with the fish immunity. GO classification had revealed on 14,489 unigenes $(63.15 \%)$ were functionally annotated to immune-related GO terms. Among the annotated categories, metabolism $(4475 ; 30.89 \%)$, stress response (1824; $12.59 \%)$ and protein metabolism $(1135 ; 7.83 \%)$ had reported on the greatest counts. KEGG pathway analysis had revealed 41 immune-related pathways, including MAPK signaling pathway, Toll-like receptor (TLR) signaling pathway, Wnt signaling pathway, NOD-like receptor signaling pathway and so on (Figure 10) (Zhenzhen et al., 2014).

Among all the components in the fish immune system, TLR family is an essential type of pattern-recognition receptors expressing on antigen-presenting cells, involved in innate immune response and the subsequent promotion of adaptive immunity (Akira et al., 2006). We had successfully identified 11 different TLRs and 12 TLR genes matched to the genome of $T$. tambroides (Table 5). The major histocompatibility complex (MHC) are the important molecules for the recognition of foreign substances via binding peptide fragments from pathogens and presenting them for T cell elimination (Neefjes et al., 2011). Both MHC class I and II had been identified in the genomic dataset as well. MHC genes serve as a candidate disease resistance marker due to their highly polymorphic characteristics in teleost (Langefors et al., 2001). Both TLR and MHC were also found within the transcriptomic dataset of Trachinotus ovatus (Zhenzhen et al., 2014). Thus, it is believed that further analysis of both genes will be able to provide insights into the immune system of $T$. tambroides as well as other teleosts. 


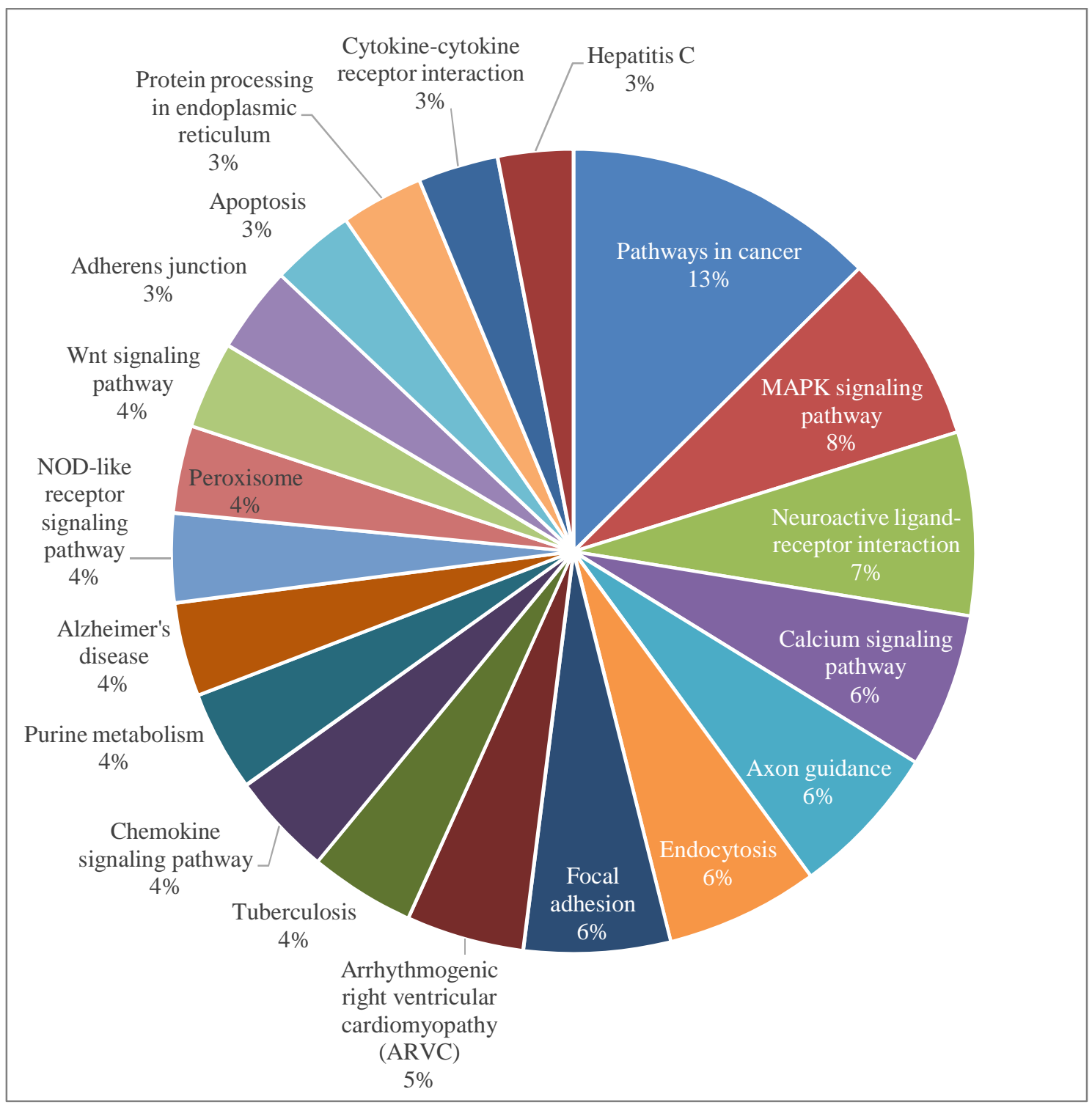

Figure 10. Top 20 annotated KEGG immune pathway of T. tambroides genome. 
Table 5. Immune-related genes. Genes marked with * asterisk sign were genes selected after e-value cutoff while best parameters were inputted for genes that did not pass the cutoff filter.

\begin{tabular}{|c|c|c|c|c|c|c|}
\hline Gene Location & Gene & Accession & $\begin{array}{l}\text { Bit } \\
\text { Score }\end{array}$ & $\begin{array}{l}\text { Aligned } \\
\text { Length }\end{array}$ & $\begin{array}{l}\text { Similarity } \\
(\%)\end{array}$ & Reference \\
\hline g81977.t1 & *60S ribosomal protein L8 & XP_034741439.1 & 469 & 234 & 97.863 & $\begin{array}{l}\text { Chandhini \& Rejish, } \\
2019\end{array}$ \\
\hline g44664.t1 & $* \mathrm{C}-\mathrm{X}-\mathrm{C}$ motif chemokine receptor 4 & BAA32797.1 & 650 & 338 & 93.491 & $\begin{array}{l}\text { Chandhini \& Rejish, } \\
2019\end{array}$ \\
\hline g54821.t1 & *Interleukin $17 \mathrm{a} / \mathrm{f} 3$ precursor & NP_001018628.1 & 181 & 162 & 62.963 & Zhenzhen et al., 2014 \\
\hline g88203.t1 & *Interleukin $17 \mathrm{C}$ & BAV01243.1 & 251 & 162 & 83.333 & Zhenzhen et al., 2014 \\
\hline g8088.t1 & *Interleukin 21 & NP_001122046.1 & 179 & 132 & 69.697 & Zhenzhen et al., 2014 \\
\hline g36229.t1 & *Interleukin 22 & NP_001018628.1 & 177 & 170 & 53.529 & Zhenzhen et al., 2014 \\
\hline g49276.t1 & *Interleukin 34 & QCX35396.1 & 365 & 209 & 85.646 & Ma et al., 2016 \\
\hline g42556.t1 & $\begin{array}{l}\text { *Myeloid differentiation primary response } \\
\text { protein } 88\end{array}$ & XP_018923074.1 & 544 & 284 & 92.254 & Zhenzhen et al., 2014 \\
\hline g48515.t1 & *Non classical MHC class I antigen & ABI21842.1 & 260 & 360 & 40.833 & Zhenzhen et al., 2014 \\
\hline g5772.t1 & *Toll-like receptor 1 & NP_001124065.1 & 659 & 402 & 79.104 & Ma et al., 2016 \\
\hline g41359.t1 & $*$ Toll-like receptor 13 & NP_001133860.1 & 736 & 915 & 45.027 & Zhenzhen et al., 2014 \\
\hline g91903.t1 & $*$ Toll-like receptor 14 & AXL48518.1 & 970 & 807 & 59.108 & Zhenzhen et al., 2014 \\
\hline g60188.t1 & *Toll-like receptor 2 precursor & NP_997977.1 & 1191 & 787 & 75.222 & Zhenzhen et al., 2014 \\
\hline
\end{tabular}




\begin{tabular}{|l|l|l|l|l|l|l|}
\hline g7235.t1 & *Toll-like receptor 21 & AVX48323.1 & 1352 & 832 & 84.014 & Ma et al., 2016 \\
\hline g41359.t1 & *Toll-like receptor 22 precursor & NP_001117884.1 & 827 & 927 & 47.249 & Ma et al., 2016 \\
\hline g42203.t1 & *Toll-like receptor 3 & ABL11473.1 & 1404 & 769 & 90.117 & Palti, 2011 \\
\hline g26383.t1 & *Toll-like receptor 4ba & AHH85806.1 & 355 & 204 & 85.784 & Palti, 2011 \\
\hline g26383.t1 & *Toll-like receptor 4bb & AHH85807.1 & 367 & 240 & 76.25 & Palti, 2011 \\
\hline g29022.t1 & *Toll-like receptor 5b precursor & NP_001124067.2 & 496 & 347 & 71.758 & Zhenzhen et al., 2014 \\
\hline g59438.t1 & *Toll-like receptor 7 & AIS23537.1 & 1360 & 1038 & 66.956 & Zhenzhen et al., 2014 \\
\hline g48547.t1 & *Toll-like receptor 9 & ADE20130.1 & 1561 & 977 & 83.419 & $\begin{array}{l}\text { Chandhini \& Rejish, } \\
\text { 2019 }\end{array}$ \\
\hline g54821.t1 & Interleukin 17N & BAV01251.1 & 44.7 & 80 & 35.000 & Zhenzhen et al., 2014 \\
\hline
\end{tabular}




\section{Growth-related Annotation}

To tap into the growth-related aspect of the $T$. tambroides genomic landscape, we functionally annotated the genome based on previously characterized growth-related genes. Table 6 shows the mapped BLAST results of immune-related genes on the genome of $T$. tambroides where there were 74 genes labelled with asterisk signs that had passed the Evalue cutoff filter of $10^{-10}$. KEGG pathway analysis revealed 19 pathways associated with growth, including pathways in cancer, insulin signaling pathway, endocytosis, focal adhesion, and mTOR signaling pathway (Zhenzhen et al., 2014) (Figure 11).

Thus, it can be said that a significant similarity had been exhibited with previously published immune-related genes. For instance, growth hormone $(\mathrm{GH})$ and insulin-like growth factorbinding protein (IGFBP) which are responsible for the regulation of GH and IGF (Zhenzhen et al., 2014) were detected in high similarity in the genome of T. tambroides (Table 6). Somatostatins were found to have an inhibitory role in promoting the release of GH ( $\mathrm{Li} \&$ Lin, 2010).

It was found out that regulation of appetite, protein and lipid metabolism, weight gain and muscle growth are also part of the complex growth process (Zhenzhen et al., 2014). A few genes related to appetite and muscle were detected in the genome of $T$. tambroides, for instance, neuropeptide Y $(N P Y)$, pro-opiomelanocortin $(P O M C)$, leptin and myostatin (Table $6)$. These genes play various roles where $N P Y$ and $P O M C$ are exerting antagonistic roles in stimulating or inhibiting feeding (Zhenzhen et al., 2014). In addition, myostatin is a negative regulator of muscle growth and its polymorphism is associated with growth traits (NadjarBoger \& Funkenstein, 2011). In addition, leptin is responsible for the regulation of energy intake and usage (Zhenzhen et al., 2014).

Moroever, genes that encode for proteolytic digestive enzymes (chymotrypsin-like elastase, cela) and are related to protein metabolism (cathepsin L, clsL and cathepsin $\mathrm{K}, c l s K$ ) were detected in the genome of $T$. tambroides as well. In addition, a number of lipid metabolism regulation genes were found in the genome of $T$. tambroides, including lipase $\mathrm{C}$ (lipC), phospholipase A2 (pla2), elongation of very long chain fatty acid family 6 (elovlo), apolipoprotein B (apob), acetyl-CoA carboxylase ( $A C A C A, A C A C B)$ and fatty acid synthase $(F A S N)$. This can be due the fact that T. tambroides is a semi-fatty fish and it contains 4.6$5.2 \%$ of muscle crude lipid (Özogul and Özogul, 2007), indicating the importance of lipid metabolism in this fish. Lipase is a key enzyme involved in lipid hydrolysis while apolipoprotein is a lipid-associated protein that regulates lipid homeostasis through the transport of triacylglycerol and phospholipid from the liver to other tissues (Infante \& Cahu, 2007). $A C A C B$ was found not only to be associated with fat yield and percentage, but it also plays role in protein yield as well (Han et al., 2018). FASN is an important element in lipid metabolism and its expression could vary due to fatty acid content in both fat and meat (Renaville et al., 2018). Furthermore, glucose-6-phosphatase ( $g 6 p c$ ) which regulates carbohydrate metabolism were detected in T. tambroides as well. These growth-related genes may serve as the possible molecular growth-related markers for further marker-assisted breeding. Further studies are required to confirm the roles of these genes in the growth of $T$. tambroides. 


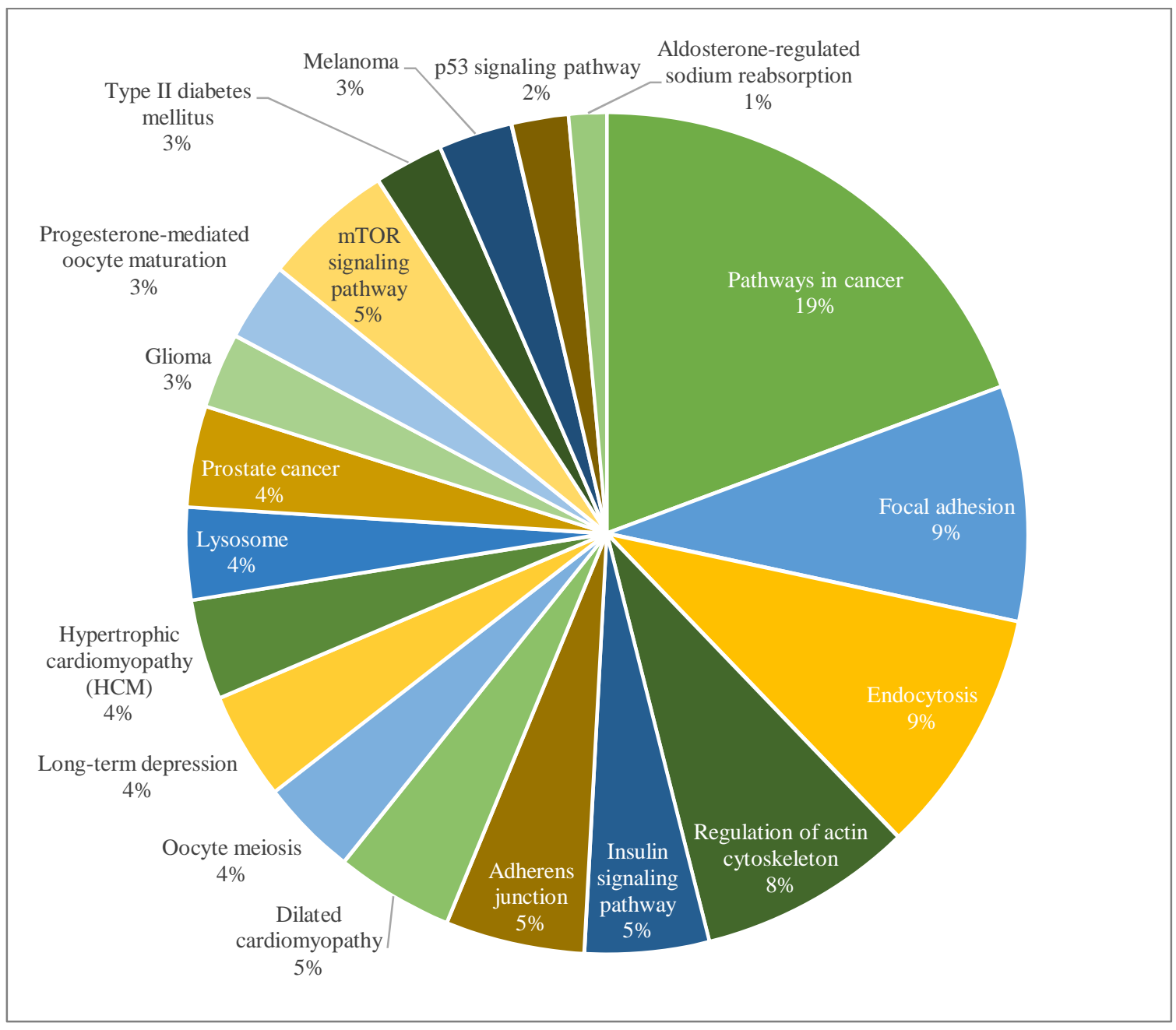

Figure 11. Annotation to growth-related KEGG pathway. 
Table 6. Growth-related genes. Genes marked with * asterisk sign were proteins selected after e-value cutoff while best parameters were input for the gene that did not pass the cutoff filter.

\begin{tabular}{|c|c|c|c|c|c|c|}
\hline Gene Location & Gene & Accession & \begin{tabular}{|l|} 
Bit \\
Score
\end{tabular} & $\begin{array}{l}\text { Aligned } \\
\text { Length }\end{array}$ & $\begin{array}{l}\text { Similarity } \\
(\%)\end{array}$ & Reference \\
\hline g79685.t1 & $\begin{array}{l}\text { *Acetyl-CoA carboxylase alpha } \\
\text { (Haplotype } 1 \text { ) }\end{array}$ & ADT82650.1 & 4772 & 2390 & 95.314 & Guan \& Qiu, 2020 \\
\hline g79685.t1 & $\begin{array}{l}\text { *Acetyl-CoA carboxylase alpha } \\
\text { (Haplotype 2) }\end{array}$ & ADX43925.1 & 4772 & 2390 & 95.816 & Guan \& Qiu, 2020 \\
\hline g44363.t1 & *Acetyl-CoA carboxylase 2 & XP_018962132.1 & 3695 & 1845 & 96.585 & Guan \& Qiu, 2020 \\
\hline g54099.t1 & *Acetyl-CoA Acetyltransferase 2 & AAD34966.1 & 751 & 395 & 92.152 & Hu et al., 2016 \\
\hline g1109.t1 & *Alpha actinin 3 & XP_031588180.1 & 1574 & 897 & 82.051 & Damzamn et al., 2020 \\
\hline g59012.t1 & *Adiponectin & NP_001373470.1 & 1574 & 897 & 82.051 & Hu et al., 2016 \\
\hline g16898.t1 & $\begin{array}{l}\text { *Alpha-1-Microglobulin/Bikunin } \\
\text { Precursor }\end{array}$ & XP_005451429.1 & 189 & 189 & 44.444 & Dam et al., 2020 \\
\hline g82874.t1 & *Apolipoprotein B & NP_001013332.1 & 407 & 259 & 78.764 & Dam et al., 2020 \\
\hline g83831.t1 & *ATP synthase & BAA82837.1 & 961 & 518 & 93.822 & Dam et al., 2020 \\
\hline g40123.t1 & *ATPase H+ transporting V1 subunit E1 & AAM34666.1 & 440 & 226 & 96.460 & Guan \& Qiu, 2020 \\
\hline g8813.t1 & $* \mathrm{G} 2 /$ mitotic-specific cyclin-B1 & NP_571588.1 & 112 & 215 & 91.071 & Guan \& Qiu, 2020 \\
\hline g31308.t1 & $*$ Cell division cycle protein 20 & NP_998245.2 & 919 & 496 & 90.726 & Guan \& Qiu, 2020 \\
\hline g3538.t1 & *Conserved Edge Expressed & ABK35126.2 & 548 & 326 & 90.184 & Overturf et al., 2010 \\
\hline g81872.t1 & $\begin{array}{l}* \text { Chymotrypsin-like elastase family } \\
\text { member } 1\end{array}$ & XP_018937349.1 & 461 & 264 & 93.561 & Dam et al., 2020 \\
\hline g49416.t1 & *Creatine kinase M-type & XP_028660838.1 & 616 & 366 & 80.874 & Damzamn et al., 2020 \\
\hline g66522.t1 & $\begin{array}{l}\text { *Peroxisomal carnitine } \mathrm{O}- \\
\text { octanoyltransferase }\end{array}$ & XP_018953213.1 & 1228 & 612 & 94.935 & Lin et al., 2019 \\
\hline g50598.t1 & *Cathepsin K precursor & NP_001017778.1 & 634 & 333 & 89.189 & Dam et al., 2020 \\
\hline $\mathrm{g} 2135 . \mathrm{t} 1$ & *Cathepsin L & AAI08032.1 & 568 & 336 & 76.786 & Dam et al., 2020 \\
\hline
\end{tabular}




\begin{tabular}{|c|c|c|c|c|c|c|}
\hline g46341.t1 & $\begin{array}{l}* 25 \text {-hydroxycholesterol_7-alpha- } \\
\text { hydroxylase }\end{array}$ & XP_699028.2 & 878 & 506 & 82.016 & Lin et al., 2019 \\
\hline g16441.t1 & *Delta-6_desaturase & AZL94116.1 & 926 & 444 & 100.00 & $\begin{array}{l}\text { Vagner \& Santiagosa, } \\
2011\end{array}$ \\
\hline g39490.t1 & $\begin{array}{l}\text { *Elongation of very long chain fatty acids } \\
\text { protein } 6\end{array}$ & XP_018957993.1 & 438 & 266 & 82.707 & Dam et al., 2020 \\
\hline g4692.t1 & $*$ Fatty acid-binding protein $10-\mathrm{A}$ & NP_694492.1_ & 240 & 126 & 90.476 & Hu et al., 2016 \\
\hline g23845.t1 & *Fatty acid synthase & ARO92273.1 & 4788 & 2486 & 94.328 & Lin et al., 2019 \\
\hline g76435.t1 & $\begin{array}{l}\text { *Farnesyl pyrophosphate synthase isoform } \\
\text { X1 }\end{array}$ & XP_005472704.1 & 608 & 359 & 81.058 & Lin et al., 2019 \\
\hline g19569.t1 & *Forkhead box protein $\mathrm{K} 1$ isoform $\mathrm{X} 1$ & XP_025764132.1 & 790 & 695 & 64.173 & Lin et al., 2019 \\
\hline g33446.t1 & $*$ G0/G1 switch protein 2 & AVM4087.1 & 215 & 112 & 91.071 & Damzamn et al., 2020 \\
\hline g51734.t1 & *Glucose-6-phosphatase & AVP32214.1 & 649 & 351 & 95.157 & Dam et al., 2020 \\
\hline g87856.t1 & *Growth hormone & CAA43007.1 & 385 & 210 & 95.238 & Ma et al., 2016 \\
\hline g40036.t1 & *Growth hormone receptor & ADZ13484.1 & 490 & 616 & 46.753 & Ma et al., 2016 \\
\hline g40036.t1 & $*$ Growth hormone receptor 1 & AAY86769.1 & 490 & 616 & 46.753 & Hu et al., 2016 \\
\hline g80039.t1 & *Glutathione synthetase & XP_018970229.1 & 883 & 475 & 90.105 & Lin et al., 2019 \\
\hline g71468.t1 & *70-kDa heat shock proteins & AAF70445.1 & 1125 & 634 & 86.278 & Hu et al., 2016 \\
\hline g74743.t1 & $\begin{array}{l}* \text { Insulin-like growth factor-binding protein } \\
1\end{array}$ & ACV72066.1 & 524 & 262 & 96.947 & Guan \& Qiu, 2020 \\
\hline g58943.t1 & $\begin{array}{l}\text { *Insulin-like growth factor-binding protein } \\
2\end{array}$ & ACM47497.1 & 548 & 274 & 97.080 & Guan \& Qiu, 2020 \\
\hline g74742.t1 & $\begin{array}{l}\text { *Insulin-like growth factor-binding protein } \\
3\end{array}$ & ACM47527.1 & 313 & 173 & 88.439 & Guan \& Qiu, 2020 \\
\hline g38084.t1 & *Inositol Monophosphatase 1 & XP_018975133.1 & 571 & 282 & 97.518 & Lin et al., 2019 \\
\hline g85602.t1 & *Insulin-induced_gene_1_protein & NP_956163.1 & 481 & 242 & 97.107 & Hu et al., 2016 \\
\hline g59760.t1 & *Leptin b1 & QEN91938.1 & 337 & 168 & 95.238 & Zhenzhen et al., 2014 \\
\hline
\end{tabular}




\begin{tabular}{|c|c|c|c|c|c|c|}
\hline g72992.t1 & *Leptin A2 & AGK24956.1 & 309 & 171 & 88.889 & Zhenzhen et al., 2014 \\
\hline g83000.t1 & *Tyrosine-protein kinase JAK2-like & XP_022620925.1 & 1602 & 967 & 78.904 & Zhenzhen et al., 2014 \\
\hline g61842.t1 & *Lipopolysaccharide binding protein & NP_001118057.1 & 672 & 469 & 69.936 & Hu et al., 2016 \\
\hline g55290.t1 & *Hepatic triacylglycerol lipase & XP_018956861.1 & 964 & 498 & 92.169 & Dam et al., 2020 \\
\hline g49598.t1 & *Myocyte Enhancer Factor 2 & BAA33567.1 & 372 & 475 & 51.158 & Overturf et al., 2010 \\
\hline g21088.t1 & *Myostatin 1 & AJF48833.1 & 515 & 351 & 68.661 & Overturf et al., 2010 \\
\hline g21088.t1 & *Myostatin 2 & AJF48834.1 & 726 & 366 & 94.536 & Overturf et al., 2010 \\
\hline g94911.t1 & $*$ Myogenic factor 5 & AWG41988.1 & 486 & 240 & 97.083 & Ma et al., 2016 \\
\hline g28564.t1 & *Neuropeptide Y receptor Y7 & NP_001007219.1 & 650 & 372 & 88.710 & Zhenzhen et al., 2014 \\
\hline g34597.t1 & *Cytochrome P450 & AAK37960.1 & 711 & 505 & 66.535 & Hu et al., 2016 \\
\hline g21266.t1 & *Paired box protein 7 isoform $\mathrm{X} 1$ & XP_013988550.1 & 580 & 496 & 62.903 & Overturf et al., 2010 \\
\hline g37657.t1 & *Cytosolic phospholipase A2 gamma-like & XP_018952444.1 & 660 & 558 & 60.394 & Dam et al., 2020 \\
\hline g45170.t1 & *Proopiomelanocortin & AAM93491.2 & 387 & 222 & 83.333 & Zhenzhen et al., 2014 \\
\hline g68580.t1 & $\begin{array}{l}\text { *Peroxisome proliferator-activated } \\
\text { receptor alpha }\end{array}$ & CAJ76702.1 & 698 & 468 & 73.077 & Hu et al., 2016 \\
\hline g41063.t1 & $\begin{array}{l}\text { *Peroxisome proliferator-activated } \\
\text { receptor beta }\end{array}$ & ACR15760.1 & 690 & 430 & 76.279 & Hu et al., 2016 \\
\hline g76564.t1 & *Preprosomatostatin I & AJB44559.1 & 218 & 114 & 96.491 & Zhenzhen et al., 2014 \\
\hline g79784.t1 & *Preprosomatostatin II & AJB44560.1 & 125 & 94 & 73.404 & Zhenzhen et al., 2014 \\
\hline g56581.t1 & *Preprosomatostatin III & AJB44561.1 & 221 & 12 & 95.833 & Zhenzhen et al., 2014 \\
\hline g42530.t1 & $*$ Prolactin & CAA31060.1 & 382 & 210 & 95.714 & Ma et al., 2016 \\
\hline g75666.t1 & *Prolactin receptor & QIB98245.1 & 1089 & 611 & 86.579 & Ma et al., 2016 \\
\hline g7570.t1 & *60S ribosomal protein L10 & XP_018921966.1 & 439 & 214 & 98.131 & Damzamn et al., 2020 \\
\hline g29499.t1 & *Antithrombin-III & XP_018920986.1 & 845 & 450 & 92.444 & Dam et al 2020 \\
\hline g81491.t1 & *SMAD family member 3 & ABI94729.1 & 877 & 423 & 99.527 & Lin et al., 2019 \\
\hline g94343.t1 & $\begin{array}{l}\text { *Secreted Protein Acidic And Cysteine } \\
\text { Rich }\end{array}$ & XP_003447656.1 & 519 & 300 & 83.667 & Lin et al., 2019 \\
\hline
\end{tabular}




\begin{tabular}{|c|c|c|c|c|c|c|}
\hline g17664.t1 & *Squalene monooxygenase & NP_001103509.1 & 970 & 528 & 89.394 & Ma et al., 2016 \\
\hline g27484.t1 & *Somatostatin Receptor type 1-like & XP_018943223.1 & 749 & 367 & 98.365 & Ma et al., 2016 \\
\hline g16955.t1 & *Somatostatin Receptor type 2-like & XP_018946514.1 & 597 & 337 & 87.834 & Zhenzhen et al., 2014 \\
\hline g82792.t1 & *Somatostatin Receptor type 3-like & XP_018963641.1 & 514 & 261 & 98.084 & Zhenzhen et al., 2014 \\
\hline g12909.t1 & *Somatostatin Receptor type 5-like & XP_018961210.1 & 661 & 443 & 81.49 & Zhenzhen et al., 2014 \\
\hline g32515.t1 & $\begin{array}{l}\text { *Signal transducer and activator of } \\
\text { transcription } 1 \mathrm{~b}\end{array}$ & NP_956385.2 & 1161 & 695 & 79.712 & Zhenzhen et al., 2014 \\
\hline g1399.t1 & $\begin{array}{l}\text { *Signal transducer and activator of } \\
\text { transcription } 2\end{array}$ & NP_001258730.1 & 1359 & 852 & 78.873 & Zhenzhen et al., 2014 \\
\hline g23419.t1 & $\begin{array}{l}\text { *Signal transducer and activator of } \\
\text { transcription } 3\end{array}$ & BAH47263.1 & 1675 & 806 & 99.256 & Zhenzhen et al., 2014 \\
\hline g28531.t1 & $\begin{array}{l}\text { *Signal transducer and activator of } \\
\text { transcription } 4\end{array}$ & NP_001004510.1 & 1324 & 679 & 95.582 & Zhenzhen et al., 2014 \\
\hline $\mathrm{g} 48083 . \mathrm{t1}$ & $\begin{array}{l}\text { *Signal transducer and activator of } \\
\text { transcription } 5\end{array}$ & BAH47264.1 & 1549 & 768 & 97.266 & Zhenzhen et al., 2014 \\
\hline $\mathrm{g} 4785 . \mathrm{t1}$ & *Ubiquitin carboxyl-terminal hydrolase 38 & XP_003449754.1 & 1415 & 1013 & 70.582 & Lin et al., 2019 \\
\hline
\end{tabular}




\section{Orthologs and Phylogenetic Inferences}

The phylogenetic relationship of $T$. tambroides with other ray-finned fishes was inferred through the BUSCO supermatrix approach through single-copy orthologs. The BUSCO completeness of each Actinopterygii species was summarized in Table 7. MUSCLE was used to align all the genomic sequences of all 53 species (Edgar, 2004). The phylogenetic tree was plotted using the maximum-likelihood model (ML; IQ-TREE) based on the single-copy and multi-copy orthologs (Figure 12). All the species fall under class Actinopterygii but belong to 18 different orders, including Cypriniformes, Perciformes, Clupeiformes, Cichliformes, Characiformes, Cyprinodontiformes, Anabantiformes, Salmoniformes, Esociformes, Gadiformes, Pleuuronectiformes, Lepisosteiformes, Atheriniformes, Beloniformes, Osteoglossiformes, Batrachoidiformes with Coelacanthiformes and Acipenseriformes rooted as outgroup. As a member of the family Cyprinidae, T. tambroides formed a monophyletic cluster with the species within order Cypriniformes, namely species from genus Sinocyclocheilus, Carassius auratus, Pimephales promelas and Danio rerio. 
Table 7. BUSCO completeness of 52 ray-finned fishes for the inference of phylogenetic relationship with T. tambroides using BUSCO supermatrix approach.

\begin{tabular}{|c|c|c|c|c|c|c|}
\hline & \multirow[t]{2}{*}{ Species } & \multicolumn{5}{|c|}{ BUSCO5 Completeness (\%) } \\
\hline & & Complete & $\begin{array}{l}\text { Complete and } \\
\text { single-copy }\end{array}$ & $\begin{array}{l}\text { Complete and } \\
\text { duplicated-copy }\end{array}$ & Fragmented & Missing \\
\hline \multirow[t]{23}{*}{ Freshwater } & Archocentrus centrarchus & 99.6 & 65.9 & 33.7 & 0.1 & 0.3 \\
\hline & Astyanax mexicanus & 98.6 & 68.6 & 30.0 & 0.7 & 0.7 \\
\hline & Austrofundulus limnaeus & 89.6 & 65.6 & 24.0 & 1.3 & 6.1 \\
\hline & Betta splendens & 99.4 & 58.6 & 40.8 & 0.2 & 0.4 \\
\hline & Carassius auratus & 99.3 & 24.6 & 74.7 & 0.2 & 0.5 \\
\hline & Colossoma macropomum & 99.7 & 70.3 & 29.4 & 0.1 & 0.2 \\
\hline & Coregonus clupeaformis & 98.6 & 38.2 & 60.4 & 0.7 & 0.7 \\
\hline & Cyprinodon tularosa & 99.0 & 71.0 & 28.0 & 0.5 & 0.5 \\
\hline & Danio rerio & 97.3 & 51.8 & 45.5 & 1.4 & 1.3 \\
\hline & Esox lucius & 99.7 & 53.6 & 46.1 & 0.1 & 0.2 \\
\hline & Etheostoma cragini & 96.5 & 58.0 & 38.5 & 1.1 & 2.4 \\
\hline & Etheostoma spectabile & 96.0 & 56.5 & 39.5 & 0.6 & 3.4 \\
\hline & Haplochromis burtoni & 98.1 & 61.4 & 36.7 & 0.8 & 1.1 \\
\hline & Lepisosteus oculatus & 94.7 & 54.4 & 40.3 & 3.4 & 1.9 \\
\hline & Melanotaenia boesemani & 99.8 & 61.4 & 38.4 & 0.0 & 0.2 \\
\hline & Oncorhynchus mykiss & 99.7 & 29.1 & 70.6 & 0.1 & 0.2 \\
\hline & Oreochromis niloticus & 99.8 & 58.1 & 41.7 & 0.1 & 0.1 \\
\hline & Oryzias latipes & 98.5 & 59.8 & 38.7 & 0.0 & 1.5 \\
\hline & Oryzias melastigma & 98.2 & 63.1 & 35.1 & 0.7 & 1.1 \\
\hline & Paramormyrops kingsleyae & 98.7 & 51.6 & 47.1 & 0.8 & 0.5 \\
\hline & Poecilia reticulata & 97.7 & 61.9 & 35.8 & 1.1 & 1.2 \\
\hline & Perca flavescens & 99.6 & 63.6 & 36.0 & 0.2 & 0.2 \\
\hline & Perca fluviatilis & 98.5 & 62.2 & 36.3 & 0.8 & 0.7 \\
\hline
\end{tabular}




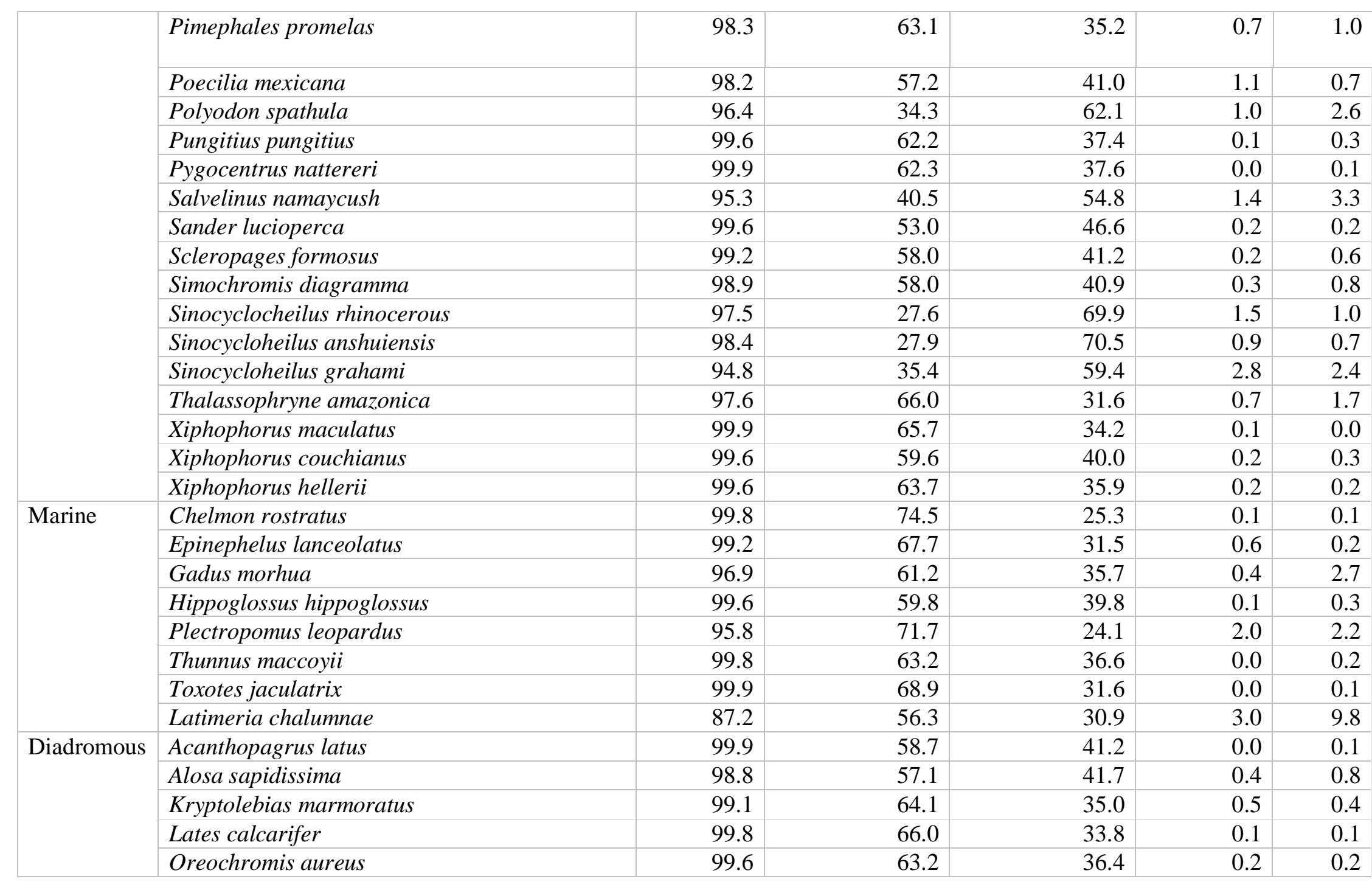


bioRxiv preprint doi: https://doi.org/10.1101/2022.01.02.474749; this version posted January 3, 2022. The copyright holder for this preprint (which was not certified by peer review) is the author/funder, who has granted bioRxiv a license to display the preprint in perpetuity. It is made available under aCC-BY-NC-ND 4.0 International license.

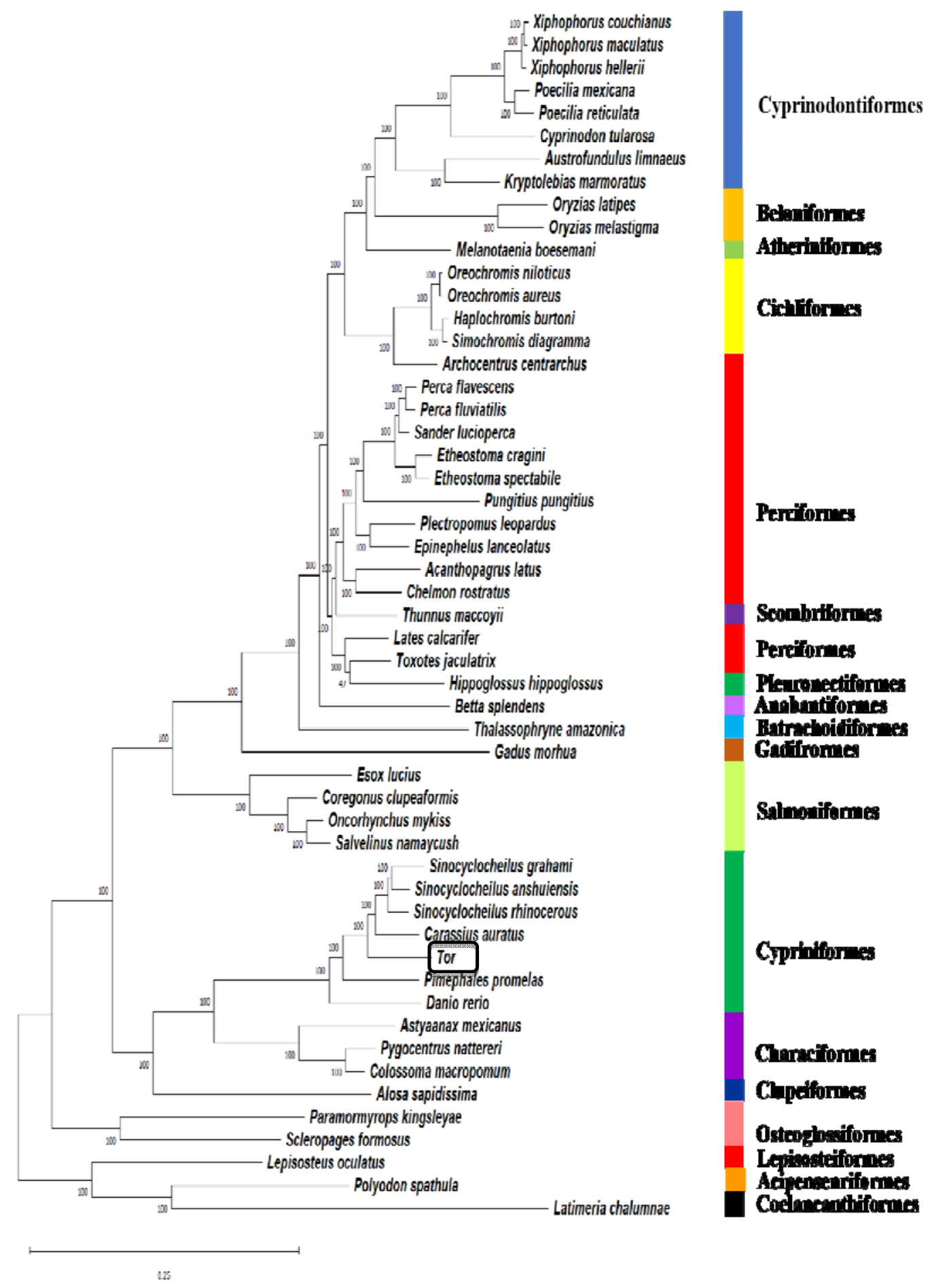

Figure 12. Maximum-likelihood tree plotted on 53 Actinopterygii species inferred from a supermatrix of 3,640 BUSCO. The species were classified based on their respective orders. 


\section{Conclusion}

We present the first Malaysian mahseer (T. tambroides) genome assembled with lowcoverage Nanopore long reads and high-coverage Illumina short reads. De novo genomic assembly had generated a draft genome with an estimated genome size of $1.5 \mathrm{~Gb}$ [84.3\% BUSCO completeness (Actinopterygii_odb10)]. 392,346 SSRs had been identified from the genome with dinucleotide repeats AT/TA as the most common SSR. A total of 96,736 nonredundant protein-coding sequences was predicted and used for later functional annotation. Predicted protein sequences had mapped to 304 known KEGG pathways with signal transduction as the highest representation. Furthermore, genes showing significant similarity to published growth- and immune-related genes were identified, hoping to serve as a potential marker for future molecular breeding of $T$. tambroides. In addition, the first genome-based evolutionary relationship of $T$. tambroides between other ray-finned fishes had been inferred using a Maximum-likelihood tree. It is hoped that this genomic data of $T$. tambroides could be a more powerful tool that continues to resolve questions of species identification, evolutionary biology, morphological variations, sequences related to sex differentiation, growth, reproduction, and immune, which are helpful for further conservation of Tor species.

\section{CrediT author statement}

Lau Melinda Mei Lin: Writing-Original Draft, Data curation, Conceptualization. Lim Leonard Whye Kit: Data Curation, Writing-Original Draft, Conceptualization. Chung Hung Hui: Conceptualization, Funding acquisition, Writing-Review and Editing. Han Ming Gan: Methodology, Conceptualization, Writing-Review and Editing.

\section{Acknowledgements}

This work was fully funded by Sarawak Research and Development Council through the Research Initiation Grant Scheme with grant number RDCRG/RIF/2019/13 awarded to H. H. Chung.

\section{Declaration of Competing Interest}

The authors declare that they have no known competing financial interests or personal relationships which have or could be perceived to have influenced the work reported in this article.

\section{References}

Abram, Q. H., Dixon, B., \& Katzenback, B. A. (2017). Impacts of low temperature on the teleost immune system. Biology, 6(4), 39.

Akira, S., Uematsu, S., \& Takeuchi, O. (2006). Pathogen recognition and innate immunity. Cell, 124(4), 783-801. 
Ashfaq, H., Soliman, H., Saleh, M., \& El-Matbouli, M. (2019). CD4: A vital player in the teleost fish immune system. Veterinary research, 50(1), 1-11.

Austin, C. M., Tan, M. H., Harrisson, K. A., Lee, Y. P., Croft, L. J., Sunnucks, P., ... \& Gan, H. M. (2017). De novo genome assembly and annotation of Australia's largest freshwater fish, the Murray cod (Maccullochella peelii), from Illumina and Nanopore sequencing read. GigaScience, 6(8), gix063.

Borodulina, O. R., Golubchikova, J. S., Ustyantsev, I. G., \& Kramerov, D. A. (2016). Polyadenylation of RNA transcribed from mammalian SINEs by RNA polymerase III: Complex requirements for nucleotide sequences. Biochimica et Biophysica Acta (BBA)- Gene Regulatory Mechanisms, 1859(2), 355-365.

Bruna, T., Hoff, K.J., Lomsadze, A., Stanke, M., \& Borodovsky, M. (2021). BRAKER2: Automatic eukaryotic genome annotation with GeneMark-EP+ and AUGUSTUS Supported by a Protein Database. NAR Genomics and Bioinformatics, 3(1).

Capella-Gutiérrez, S., Silla-Martínez, J. M., \& Gabaldón, T. (2009). trimAl: A tool for automated alignment trimming in large-scale phylogenetic analyses. Bioinformatics, 25(15), 1972-1973.

Chandhini, S., \& Rejish Kumar, V. J. (2019). Transcriptomics in aquaculture: Current status and applications. Reviews in Aquaculture, 11(4), 1379-1397.

Chen, S., Zhou, Y., Chen, Y., \& Gu, J. (2018). fastp: an ultra-fast all-in-one FASTQ preprocessor. Bioinformatics, 34(17), i884-i890.

Dam, C. T. M., Ventura, T., Booth, M., Pirozzi, I., Salini, M., Smullen, R., \& Elizur, A. (2020). Intestinal transcriptome analysis highlights key differentially expressed genes involved in nutrient metabolism and digestion in yellowtail kingfish (Seriola lalandi) fed terrestrial animal and plant proteins. Genes, 11(6), 621.

Danzmann, R. G., Kocmarek, A. L., Norman, J. D., Rexroad, C. E., \& Palti, Y. (2016). Transcriptome profiling in fast versus slow-growing rainbow trout across seasonal gradients. BMC Genomics, 17(1), 1-18.

Di Genova, A., Buena-Atienza, E., Ossowski, S., \& Sagot, M. F. (2021). Efficient hybrid de novo assembly of human genomes with WENGAN. Nature Biotechnology, 39(4), 422-430.

Eckert, K. A., Yan, G., \& Hile, S. E. (2002). Mutation rate and specificity analysis of tetranucleotide microsatellite DNA alleles in somatic human cells. Molecular Carcinogenesis: Published in cooperation with the University of Texas MD Anderson Cancer Center, 34(3), 140-150.

Edgar, R. C. (2004). MUSCLE: Multiple sequence alignment with high accuracy and high throughput. Nucleic acids research, 32(5), 1792-1797.

Firdaus-Nawi, M., and Zamri-Saad, M. (2016). Major components of fish immunity: A review. Pertanika Journal of Tropical Agricultural Science, 39, 393-420. 
Guan, W. Z., \& Qiu, G. F. (2020). Transcriptome analysis of the growth performance of hybrid mandarin fish after food conversion. PloS One, 15(10), e0240308.

Han, B., Liang, W., Liu, L., Li, Y., \& Sun, D. (2018). Genetic association of the ACACB gene with milk yield and composition traits in dairy cattle. Animal genetics, 49(3), 169-177.

Heather, J. M., \& Chain, B. (2016). The sequence of sequencers: The history of sequencing DNA. Genomics, 107(1), 1-8.

Hoang, H. D., Pham, H. M., Durand, J. D., Tran, N. T., \& Phan, P. D. (2015). Mahseers genera Tor and Neolissochilus (Teleostei: cyprinidae) from southern Vietnam. Zootaxa, 4006(3), 551-568.

Hong, J. (1998). The distribution trends in simple repetitive stretches of DNA. Chinese Journal of Biochemistry and Molecular Biology, 14(1), 65-70.

Hu, G., Gu, W., Sun, P., Bai, Q., \& Wang, B. (2016). Transcriptome analyses reveal lipid metabolic process in liver related to the difference of carcass fat content in rainbow trout (Oncorhynchus mykiss). International Journal of Genomics, 2016.

Infante, J. Z., \& Cahu, C. L. (2007). Dietary modulation of some digestive enzymes and metabolic processes in developing marine fish: Applications to diet formulation. Aquaculture, 268(1-4), 98-105.

Ingram, B., Sungan, S., Gooley, G., Sim, S. Y., Tinggi, D., \& De Silva, S. S. (2005). Induced spawning, larval development and rearing of two indigenous Malaysian mahseer, Tor tambroides and T. douronensis. Aquaculture research, 36(10), 983-995.

Jaafar, F., Na-Nakorn, U., Srisapoome, P., Amornsakun, T., Duong, T. Y., Gonzales-Plasus, M. M., ... \& Parhar, I. S. (2021). A current update on the distribution, morphological features, and genetic identity of the Southeast Asian Mahseers, Tor species. Biology, 10(4), 286.

Jones, P., Binns, D., Chang, H. Y., Fraser, M., Li, W., McAnulla, C., ... \& Hunter, S. (2014). InterProScan 5: Genome-scale protein function classification. Bioinformatics, 30(9), 1236-1240.

Kim, D., Langmead, B., \& Salzberg, S. L. (2015). HISAT: A fast spliced aligner with low memory requirements. Nature Methods, 12(4), 357-360.

Kottelat, M. (2000). Notes on the taxonomy, nomenclature and distribution of some fishes of Laos. Journal of South Asian Natural History, 5(1), 83-90.

Kottelat, M., Pinder, A. C., \& Harrison, A. (2018). Tor tambra. The IUCN Red List of Threatened Species, (2018-2).

Kumar, S., Stecher, G., Li, M., Knyaz, C., \& Tamura, K. (2018). MEGA X: Molecular evolutionary genetics analysis across computing platforms. Molecular biology and evolution, 35(6), 1547.

Langefors, Å., Lohm, J., Grahn, M., Andersen, Ø., \& Schantz, T. V. (2001). Association between major histocompatibility complex class IIB alleles and resistance to 
Aeromonas salmonicida in Atlantic salmon. Proceedings of the Royal Society of London. Series B: Biological Sciences, 268(1466), 479-485.

Lau, M. M. L., Kho, C. J. Y., Lim, L. W. K., Sia, S. C., Chung, H. H., Lihan, S., \& Apun, K. (2021c). Microbiome analysis of gut bacterial communities of healthy and diseased Malaysian mahseer (Tor tambroides). bioRxiv doi: 10.1101/2021.12.08.471852

Lau, M. M. L., Lim, L. W. K., Chung, H. H., \& Gan, H. M. (2021b). The first transcriptome sequencing and data analysis of the Javan mahseer (Tor tambra). Data in Brief, 39, 107481.

Lau, M. M. L., Lim, L. W. K., Ishak, S. D., Abol-Munafi, A. B., \& Chung, H. H. (2021a). A review on the emerging Asian aquaculture fish, the Malaysian mahseer (Tor tambroides): Current status and the way forward. In Proceedings of the Zoological Society, 1-11. Springer India.

Lei, Y., Zhou, Y., Price, M., \& Song, Z. (2021). Genome-wide characterization of microsatellite DNA in fishes: survey and analysis of their abundance and frequency in genome-specific regions. BMC genomics, 22(1), 1-22.

Li, W., \& Lin, H. (2010). The endocrine regulation network of growth hormone synthesis and secretion in fish: Emphasis on the signal integration in somatotropes. Science China Life Sciences, 53(4), 462-470.

Lien, S., Koop, B. F., Sandve, S. R., Miller, J. R., Kent, M. P., Nome, T., ... \& Davidson, W. S. (2016). The Atlantic salmon genome provides insights into rediploidization. Nature,533(7602), 200-205.

Lim, L. W. K., Tan, H. Y., Aminan, A. W., Jumaan, A. Q., Moktar, M. Z., Tan, S. Y., Balinu, C. P., Robert, A. V., Chung, H. H., \& Sulaiman, B. (2018). Phylogenetic and expression of ATP-binding cassette transporter genes in Rasbora sarawakensis. Pertanika Journal of Tropical Agricultural Science, 41(3), 1341-1354.

Lim, L. W. K., Chung, H. H., Lau, M. M. L., Aziz, F., \& Gan, H. M. (2021a). Improving the phylogenetic resolution of Malaysian and Javan mahseer (Cyprinidae), Tor tambroides and Tor tambra: Whole mitogenomes sequencing, phylogeny and potential mitogenome markers. Gene, 791, 145708.

Lim, L. W. K., Chung, H. H., Ishak, S. D., \& Waiho, K. (2021b). Zebrafish (Danio rerio) ecotxicological ABCB4, ABCC1 and ABCG2a gene promoters depict spatiotemporal xenobiotic multidrug resistance properties against environmental pollutants. Gene Reports, 23, 101110.

Lim, L. W. K., Chung, H. H., Hussain, H., \& Gan, H. M. (2021c). Genome survey of sago palm (Metroxylon sagu Rottboll). Plant Gene, 28, 100341.

Lim, L. W. K., Lau, M. M. L., Chung, H. H., Hussain, H., \& Gan, H. M. (2022). First highquality genome assembly data of sago palm (Metroxylon sagu Rottboll). bioRxiv doi: 10.1101/2022.1.1.474478 
Lin, G., Thevasagayam, N. M., Wan, Z. Y., Ye, B. Q., \& Yue, G. H. (2019). Transcriptome analysis identified genes for growth and omega-3/-6 ratio in saline tilapia. Frontiers in Genetics, 10, 244.

Lu, G., \& Luo, M. (2020). Genomes of major fishes in world fisheries and aquaculture: Status, application and perspective. Aquaculture and Fisheries, 5(4), 163-173.

Ma, D., Ma, A., Huang, Z., Wang, G., Wang, T., Xia, D., \& Ma, B. (2016). Transcriptome analysis for identification of genes related to gonad differentiation, growth, immune response and marker discovery in the turbot (Scophthalmus maximus). PLoS One, 11(2), e0149414.

Manni M, Berkeley MR, Seppey M, Simão FA, Zdobnov EM. 2021. BUSCO update: Novel and streamlined workflows along with broader and deeper phylogenetic coverage for scoring of eukaryotic, prokaryotic, and viral genomes. Molecular Biology and Evolution.

Marçais, G., \& Kingsford, C. (2011). A fast, lock-free approach for efficient parallel counting of occurrences of kmers. Bioinformatics Methods and Protocols, 27(6), 764-770.

Mikheenko, A., Prjibelski, A., Saveliev, V., Antipov, D., \& Gurevich, A. (2018). Versatile genome assembly evaluation with QUAST-LG. Bioinformatics, 34(13), i142-i150.

Nadjar-Boger, E., \& Funkenstein, B. (2011). Myostatin-2 gene structure and polymorphism of the promoter and first intron in the marine fish Sparus aurata: Evidence for DNA duplications and/or translocations. BMC genetics, 12(1), 1-19.

Natnan, M. E., Low, C. F., Chong, C. M., Bunawan, H., \& Baharum, S. N. (2021). Integration of omics tools for understanding the fish immune response due to microbial challenge. Frontiers in Marine Science, 8, 751.

Neefjes, J., Jongsma, M. L., Paul, P., \& Bakke, O. (2011). Towards a systems understanding of MHC class I and MHC class II antigen presentation. Nature Reviews Immunology, $11(12), 823-836$.

Ng, C. K. (2004). Kings of the river-Mahseer in Malaysia and the region. Kuala Lumpur, Malaysia: Inter Sea Fishery.

Nguyen, L. T., Schmidt, H. A., Von Haeseler, A., \& Minh, B. Q. (2015). IQ-TREE: A fast and effective stochastic algorithm for estimating maximum-likelihood phylogenies. Molecular Biology and Evolution, 32(1), 268-274.

Overturf, K., Sakhrani, D., \& Devlin, R. H. (2010). Expression profile for metabolic and growth-related genes in domesticated and transgenic coho salmon (Oncorhynchus kisutch) modified for increased growth hormone production. Aquaculture, 307(1-2), 111-122.

Özogul, Y., \& Özogul, F. (2007). Fatty acid profiles of commercially important fish species from the Mediterranean, Aegean and Black Seas. Food Chemistry, 100(4), 16341638. 
Palti, Y. (2011). Toll-like receptors in bony fish: From genomics to function. Developmental \& Comparative Immunology, 35(12), 1263-1272.

Pickett, B. D., Miller, J. B., \& Ridge, P. G. (2017). Kmer-SSR: A fast and exhaustive SSR search algorithm. Bioinformatics, 33(24), 3922-3928.

Renaville, B., Bacciu, N., Lanzoni, M., Mossa, F., \& Piasentier, E. (2018). Association of single nucleotide polymorphisms in fat metabolism candidate genes with fatty acid profiles of muscle and subcutaneous fat in heavy pigs. Meat Science, 139, 220-227.

Riera Romo, M., Pérez $\square$ Martínez, D., \& Castillo Ferrer, C. (2016). Innate immunity in vertebrates: An overview. Immunology, 148(2), 125-139.

Roberts, T. R. (1999). Fishes of the cyprinid genus Tor in the Nam Theun watershed (Mekong basin) of Laos, with description of a new species. Raffles Bulletin of Zoology, 47, 225-236.

Roberts, T. R. and M. Z. Khaironizam (2008). Trophic polymorphism in the Malaysian fish Neolissochilus soroides and other old world barbs (Teleostei, Cyprinidae). Natural History Bulletin of the Siam Society, 56, 25-53.

Sales, C. F., Silva, R. F., Amaral, M. G., Domingos, F. F., Ribeiro, R. I., Thomé, R. G., \& Santos, H. B. (2017). Comparative histology in the liver and spleen of three species of freshwater teleost. Neotropical Ichthyology, 15(1).

Salinas, I., \& Magadán, S. (2017). Omics in fish mucosal immunity. Developmental \& Comparative Immunology, 75, 99-108.

Schlötterer, C. (2000). Evolutionary dynamics of microsatellite DNA. Chromosoma, 109(6), $365-371$.

Shreshtha, T. K. (1997). The Mahseer in the rivers of nepal disrupted by dams and ranching strategies (p. 271). Kathmandu, Nepal: Mrs. Bimala Shrestha.

Smith, N. C., Rise, M. L., \& Christian, S. L. (2019). A comparison of the innate and adaptive immune systems in cartilaginous fish, ray-finned fish, and lobe-finned fish. Frontiers in immunology, 10, 2292.

Tan, M. H., Austin, C. M., Hammer, M. P., Lee, Y. P., Croft, L. J., \& Gan, H. M. (2018). Finding Nemo: Hybrid assembly with Oxford Nanopore and Illumina reads greatly improves the clownfish (Amphiprion ocellaris) genome assembly. GigaScience, 7(3), gix 137.

Tóth, G., Gáspári, Z., \& Jurka, J. (2000). Microsatellites in different eukaryotic genomes: Survey and analysis. Genome research, 10(7), 967-981.

Vagner, M., \& Santigosa, E. (2011). Characterization and modulation of gene expression and enzymatic activity of delta-6 desaturase in teleosts: A review. Aquaculture, 315(1-2), 131-143.

Vurture, G. W., Sedlazeck, F. J., Nattestad, M., Underwood, C. J., Fang, H., Gurtowski, J., \& Schatz, M. C. (2017). GenomeScope: Fast reference-free genome profiling from short reads. Bioinformatics, 33(14), 2202-2204. 
Wang, Y., Lu, Y., Zhang, Y., Ning, Z., Li, Y., Zhao, Q., ... \& Zhu, Z. (2015). The draft genome of the grass carp (Ctenopharyngodon idellus) provides insights into its evolution and vegetarian adaptation. Nature genetics, 47(6), 625-631.

Wick, R. R., Judd, L. M., Gorrie, C. L., \& Holt, K. E. (2017). Completing bacterial genome assemblies with multiplex MinION sequencing. Microbial Genomics, 3(10).

Xu, P., Zhang, X., Wang, X., Li, J., Liu, G., Kuang, Y., ... \& Sun, X. (2014). Genome sequence and genetic diversity of the common carp, Cyprinus carpio. Nature genetics, $46(11), 1212-1219$.

Yuan, Z., Liu, S., Zhou, T., Tian, C., Bao, L., Dunham, R., \& Liu, Z. (2018). Comparative genome analysis of 52 fish species suggests differential associations of repetitive elements with their living aquatic environments. BMC genomics, 19(1), 1-10.

Zhenzhen, X., Ling, X., Dengdong, W., Chao, F., Qiongyu, L., Zihao, L., ... \& Haoran, L. (2014). Transcriptome analysis of the Trachinotus ovatus: Identification of reproduction, growth and immune-related genes and microsatellite markers. PloS one, 9(10), e109419. 